\title{
Alphaherpesvirus Latency and Reactivation with a Focus on Herpes Simplex Virus
}

\author{
Nancy M. Sawtell ${ }^{1 *}$ and Richard L. Thompson ${ }^{2 *}$
}

${ }^{1}$ Infectious Diseases, Cincinnati Children's Hospital Medical Center, 3333 Burnet Ave, Cincinnati Ohio, 45229-3039, USA

${ }^{2}$ Molecular Genetics, Microbiology, and Biochemistry, University of Cincinnati College of Medicine, 231 Albert Sabin Way, Cincinnati, Ohio, 45267-0524, USA

*nancy.sawtell@cchmc.org, richard.thompson@uc.edu

DOI: https://doi.org/10.21775/cimb.041.267

\begin{abstract}
We are at an interesting time in the understanding of alpha herpesvirus latency and reactivation and their implications to human disease. Conceptual advances have come from both animal and neuronal culture models. This review focuses on the concept that the tegument protein and viral transactivator VP16 plays a major role in the transition from latency to the lytic cycle. During acute infection, regulation of VP16 transactivation balances spread in the nervous system, establishment of latent infections and virulence. Reactivation is dependent on this transactivator to drive entry into the lytic cycle. In vivo de novo expression of VP16 protein is mediated by sequences conferring pre-immediate early transcription embedded in the normally leaky late promoter. In vitro, alternate mechanisms regulating VP16 expression in the context of latency have come from the SCG neuron culture model and include the concepts that (i) generalized transcriptional derepression of the
\end{abstract}


viral genome and sequestration of VP16 in the cytoplasm for $\sim 48$ hours (Phase I) precedes and is required for VP16-dependent reactivation (Phase II); and (ii) a histone methyl/phospho switch during Phase I is required for Phase II reactivation. The challenge to the field is reconciling these data into a unified model of virus reactivation.

The greatest enemy of knowledge is not ignorance, it is the illusion of knowledge.-- Daniel J. Boorstin.

The task of compiling this review was uncomfortably humbling, as if cataloging the stars in the universe. While not completely dark, our night sky is missing a multitude of studies which are among the many points of light contributing to our field. This article is a focused review in which we discuss from the vantage point of our expertise, just a handful of concepts that have or are emerging. A lookback at some of the pioneering work that grounds our field is also included.

\section{Introduction}

The mechanisms of latency and reactivation of the human alpha herpesviruses, herpes simplex virus 1 and 2 (HSV1, HSV2) and varicella zoster virus (VZV), remain major unsolved mysteries. Each year, recurrent HSV disease contributes to $\sim 200$ million new HSV infections (worldwide, extrapolated from US infection rates) (Azwa and Barton, 2009; Pepose et al., 2006), two-thirds of new sexually acquired HIV infections (Glynn et al., 2009), $\sim 10$ million cases of eye disease (Pepose et al., 2006), $\sim 150,000$ cases of encephalitis (Stone and Hawkins, 2007), and devastating neonatal disease (Looker et al., 2017; Roberts, 2009). Herpesvirus infections are also linked to type II diabetes (Sun et al., 2005), cardiovascular disease (Mukamal et al., 2004; Visser and Vercellotti, 1993), and now strongly implicated in Alzheimer's disease (Fulop et al., 2018; Itzhaki, 2018; Itzhaki and Wozniak, 2008; Lathe et al., 2019). The ubiquity of HSV results from the ability of the virus to establish latent infections that periodically reactivate and transmit the infection to new hosts (Ahmed and Stevens, 1990; Knipe, 2007; Roizman et al.). 
The availability of animal models that support HSV latency and reactivation, and the work of many laboratories over many years, have contributed to a collective understanding of the HSV life cycle. Infection occurs at the body surface, usually a mucosal epithelium, where the virus replicates, spreads, and gains access to the innervating neuron axonal endings. At this point, nucleocapsids deposited into the axonal cytosol use retrograde axonal transport to reach neuronal cell bodies that are housed within peripheral ganglia (a collection of sensory or autonomic nerve cell bodies innervating specific tissues). The trigeminal ganglia (TG), which innervate the oral mucosa and other regions of the face, is the typical site of HSV1 latent infection, whereas the sacral ganglia (SG) innervates the genital mucosa and serves as the predominant site of latent HSV2 infection.

\section{Overview}

Our current understanding of HSV latency and reactivation arises out of a blend of human studies and findings from various animal and neuronal culture models. It is important to recognize the limitations of these models when summing up what we know. Importantly, new technologies and approaches with increased sensitivity have driven new waves of data acquisition which requires assimilation into what we think we know about an extremely complex process. There is increasing evidence for the concept that HSV1 latency/ reactivation can be a risk factor in the development of neurodegenerative disorders. Also arising from the human model, the concept of "continuous" ganglionic reactivation has emerged as an explanation for the unexpectedly high frequency of viral DNA in human genital swabs in some patients in the absence of detectable infectious virus.

This article focuses on an unexpected observation that the tegument protein and viral transactivator, VP16, plays a major role in the transition from latent into the lytic cycle and is required for balancing the latent/lytic transition (Figure 1). During acute infection, regulation of VP16 transactivation balances spread into the nervous system, establishment of latency, and virulence. In 


\section{VP16 and the establishment of the latent reservoir and control of virulence}
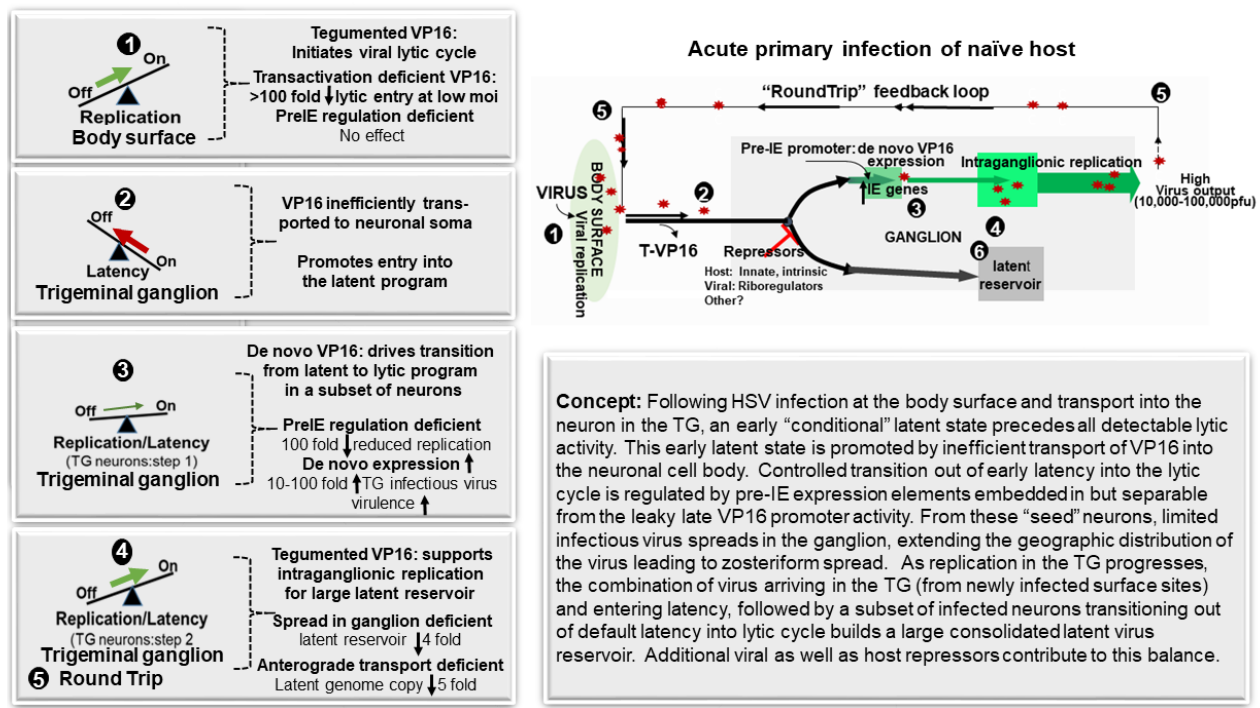

Concept: Following HSV infection at the body surface and transport into the neuron in the TG, an early "conditional" latent state precedes all detectable lytic activity. This early latent state is promoted by inefficient transport of VP16 into the neuronal cell body. Controlled transition out of early latency into the lytic cycle is regulated by pre-IE expression elements embedded in but separable from the leaky late VP16 promoter activity. From these "seed" neurons, limited infectious virus spreads in the ganglion, extending the geographic distribution of the virus leading to zosteriform spread. As replication in the TG progresses, the combination of virus arriving in the TG (from newly infected surface sites) and entering latency, followed by a subset of infected neurons transitioning out of default latency into lytic cycle builds a large consolidated latent virus reservoir. Additional viral as well as host repressors contribute to this balance.

Reactivation and maintenance of latency

Concept:1 Latency consolidates over time and a stable reservoir of latent viral genomes is maintained in ganglionic neurons. Spontaneous reactivation occurs at a low rate (1 in 120,000 latently infected neurons). 2 Stressors can increase the probability of reactivation 60 fold, representing $~ 0.05 \%$ of latently infected neurons. Changes in repressive chromatin on the viral genome appear to be a global response. (3) However, de novo VP16 expression is required for initiating a productive lytic cycle from the latent genome.4 Consistent with the $\sim 3$ neurons undergoing reactivation, low levels of infectious virus are produced and transported to the surface where replication in epithelial cells can lead to transmission to new host.5

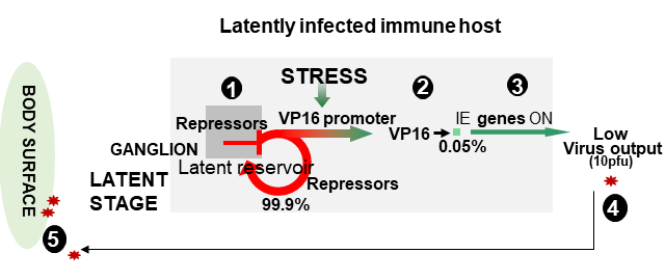

Figure 1. Regulation of VP16 function balances latent/lytic programs. Entering the neuron: The VP16 tegument protein, which is a potent transactivator of viral immediate-early gene expression, is not available to perform this function in neurons infected via axonal endings because of inefficient transport of VP16 via axon to the cell body during acute infection. The viral DNA enters the nucleus where it forms a circular episome and becomes associated with nucleosomes, which promotes the latent transcriptional program.

turn, reactivation is dependent on this transactivator to drive entry into the lytic cycle. A potential mechanism for regulating VP16 expression in the context of in vitro latency has come from the superior cervical ganglion (SCG) neuron culture model (Cliffe et al., 2015; Kim et al., 2012). The concepts that have 
emerged from this work are as follows: (i) generalized derepression of the viral genome (Phase I) precedes VP16-dependent reactivation and is required for it (Phase II), and (ii) a histone methyl/phospho switch during Phase I is required for Phase II reactivation. Notably, in vitro neuronal models of latency vary in this regard and some do not display this dual phase reactivation mechanism (Edwards and Bloom, 2019). It will be important to reconcile the findings in diverse in vitro and in vivo models of alpha herpesvirus latency and reactivation to develop testable hypotheses and determine relevant regulatory molecular mechanisms. To frame the present, we start by discussing the early seminal findings.

Creating the latent reservoir: The latent reservoir (which is essential for viral reactivation) is established upon HSV1 reaching neuronal nuclei. The number of latently infected neurons and the number viral genomes residing within each neuron are important parameters that contribute to the potential of future reactivation events. Although latency is the default outcome of neuronal infection in some neurons, HSV1 enters the lytic cycle during acute infection initiated via prelE expression of VP16. This regulated entry into the lytic cycle in the ganglionic neuron modulates virulence while supporting the viral replication that ultimately increases the size of the latent reservoir in the ganglia which occurs during this acute stage of infection. Virus produced in the ganglion is transported back to the body surface, resulting in a positive feedback loop and zosteriform spread. Exit from this "default latency" pathway is balanced by negative factors such as virus and host riboregulators including microRNAs that target viral genes, other repressors such as intrinsic immune functions (promyelocytic leukemia bodies $(\mathrm{PML})$ ) and positive factors (de novo VP16, multiple viral genome copies).

Preserving the latent reservoir: During latent infection, modification in the chromatin associated with the viral genome evolves into an increasingly repressive state. Despite this repression, there is a low level of transcription from the genome related to lytic genes. The significance of this transcription is not known but could reflect a repressive mechanism working in tandem with 
the LATs and microRNAs. Replicating virus and viral proteins are not detected during latency in the TG. Long-term studies in the mouse and rabbit reveal the latent reservoir appears to be stable. Expression from the LAT locus is important to maintain reactivation competent latent infections.

Reactivation. Stress results in de novo expression of VP16 which coordinates activation of the viral immediate-early (IE) genes. A productive lytic cycle ensues in $0.05 \%$ of latently infected neurons per event although more generalized changes in the chromatin associated with the latent genomes occurs. Thus, HSV has devised a complex regulatory strategy that maintains the vast majority of its latent genomes in latency, while allowing the release into a productive lytic cycle in an extremely rare number of neurons. During reactivation, virus does not spread to neighboring neurons in the ganglia but is transported back the body surface where subsequent replication in epithelial cells amplifies virus output and facilitates transmission to new hosts. Spontaneous reactivation in sensory ganglia has been documented in mouse models. Adapted from (Thompson et al., 2009).

\section{How 150 years of research have shaped our ideas about herpesvirus pathogenesis}

The earliest scientific investigations on alpha herpesvirus latency were primarily clinical observations. Herpes, an ancient Greek word meaning "to creep", was used by Hippocrates to describe diverse skin diseases. The association between fever and blisters around the mouth and nose was recognized nearly 2500 years ago by the Roman physician Herodotus who described herpes febrilis (Wildy, 1973). The terms "fever blisters" and "cold sores" are still in use today. Through the ensuing millennia the recurrent nature of these types of diseases was appreciated. 
Why do herpetic lesions recur? Are they from an infectious agent? What is the nature of the agent?

1863-1930s. Available Toolbox:

- Knowledge of transmission of infection and infectious agents including bacteria and "filterable agents" (the latter the earliest indication of viruses)

- Koch's famous postulates delivered in 1890 (Koch, 1890)

- Identification of a "neutralizing" substance in the blood that countered infections (Behring and Kitasato, 1890)

- Generation of these neutralizing substances, including those to herpes simplex

- Methods to store or serially passage herpes in animal brains (Perdrau, 1925)

- Light microscopy combined with histological staining to study tissue.

Neurons distinguished from other cells used in conjunction with agents transmitted through nerves contributed to knowledge of brain structure and innervation from the periphery (Doer, 1920; Friedenwald, 1923;

Goodpasture and Teague, 1923)

The association of herpetic lesions with the nervous system was appreciated as early as the mid-19th century (Von Barensprung, 1863). However, it was not until the beginning of the 20th century that clinicians and scientists began to appreciate a relationship between herpetic lesions on the body surface and the sensory nerve endings innervating the skin. In 1892 von Bokay observed that children often developed varicella after exposure to an adult suffering from zoster (von Bokay, 1909). In 1900 Head and Campbell deduced from the pattern of lesions on their patients that herpes zoster must be related to sensory ganglia. Their tour-de-force study (Head and Campbell, 1900), reprinted in part in 1997 (Head et al., 1997), was the first to show how herpetic viral diseases can be employed to help understand the anatomy of the nervous system, a practice that continues today (Sarno and Robison, 2018). Relying heavily on their work, Howard noted that human herpetic lesions of the face were associated with trigeminal ganglionitis and pneumonitis early in the 20th century (Howard, 1903). At about the same time Cushing reported that 
some individuals treated for trigeminal neuralgia by surgical resection of the trigeminal ganglion and nerve roots developed herpetic lesions in areas innervated by the contralateral (opposite side) nerve but not on the ipsilateral (resected) side (Cushing, 1905), supporting the hypothesis that herpetic lesions were associated with stress or damage to the peripheral nervous system.

Vidal first demonstrated the infectious nature of herpes (Vidal, 1873), but of greater significance to those interested in latency were later studies involving transmission of herpetic stromal keratitis. At the end of World War I the transmission of human herpetic stromal keratitis to rabbit corneas by Gruter (Gruter, 1920; Kraupa, 1920) and Loewenstein (Loewenstein, 1919, 1920) and subsequently transmission back to a human (reviewed in (Holden, 1932)) cemented the idea that herpes was an infectious agent, and provided an animal model for study. During this same time, varicella was transmitted to naive children using vesicle fluid from children with varicella lesions (Kundratitz, 1925); however, attempts to infect laboratory animals failed (Rivers and Tillett, 1924). The lack of an animal model is a difficult challenge for the study of VZV pathogenesis and latency that persists to the present day (Mahalingam et al., 2019; Ouwendijk and Verjans, 2015). A creative approach to overcome the species specificity of VZV is the use of human tissue xenografts in mice with severe combined immunodeficiency (SCID). This model allows the analysis of VZV infection in differentiated human cells in the context appropriate tissue microenvironments, providing many insights into VZV pathogenesis (Moffat et al., 1995; Zerboni and Arvin, 2015; Zerboni et al., 2014). More recent studies using dissociated human TG have provided insight into VZV reactivation (Cohrs et al., 2017).

Several groups noted that herpes infection on the rabbit eye led to infection of the central nervous system (CNS) and changes in rabbit behavior (e.g. turning the head to a particular side), both suggesting a neural route of transmission (Doer, 1920; Friedenwald, 1923; Goodpasture and Teague, 1923). Goodpasture began a series of histological studies delineating herpes spread 
within rabbits (Goodpasture, 1925a, b; Goodpasture and Teague, 1923) that culminated in the astounding and prescient conclusion that: "Following a primary infection, it seems quite probable that the virus remains in a latent state within the ganglia after the local lesion has healed. A second cutaneous eruption may occur as a result of injury...or the disturbed physiological states... which sets in activity a latent virus" (Goodpasture, 1929). Despite the seemingly overwhelming evidence of nerve involvement in herpes infection this idea was not universally accepted.

1930s-1980s. Toolbox additions include:

- The nature of viruses (Stanely, 1935)

- Tissue and virus culture as well as plaque assays for animal viruses (Dulbecco and Vogt, 1953)

- Ultra-low freezers for virus storage

- Electron microscopy

- Refined histological approaches, fixation methods and immunohistochemistry;

- Conditionally lethal viral mutants

- The "phage Church" and Lambda phage latency, DNA structure and code (Watson and Crick, 1953)

- The central dogma of DNA to RNA to protein

- Liquid DNA/RNA hybridizations

- Bacterial restriction-modification system (S.E. and M.L., 1952) and commercial restriction enzymes

- In situ hybridization for DNA and RNA (Gall and Pardue, 1969)

- Radiolabeling of proteins and nucleic acids and various separation methods including chromatography, electrophoretic gel systems, and blotting and probing (Southern, 1975)

- Cloning and cloning vectors (Bolivar et al., 1977)

- Engineered viral mutations

- Genetically modified and engineered animal models, especially mice

- Maxim and Gilbert, then Sanger sequencing 
Good and Campbell employed Perdrau's rabbit model of herpetic encephalitis (Perdrau, 1925, 1938) to demonstrate that anaphylactic shock could "precipitate" herpetic encephalitis in previously infected rabbits pre-sensitized to egg albumin (Good and Campbell, 1948). Rabbits were infected with HSV and one to three months after they appeared to be disease free, anaphylactic shock was induced by exposure to egg albumin. Encephalitis occurred in $19 / 44$ tests and virus was recovered from the brains of all rabbits that died and many that recovered. Virus was not detected in the brains of rabbits prior to anaphylaxis. Arguably this was the first well controlled evidence of latency and reactivation of $\mathrm{HSV}$ in the nervous system in vivo. We now know that intramuscular injection of HSV most likely resulted in virus replication in the skin at the site of injection and subsequent spread to the innervating sensory ganglia. Anaphylactic shock presumably caused virus reactivation within sensory neurons with subsequent spread to the brain resulting in fatal encephalitis but virus reactivation within brain neurons was not ruled out.

Schmidt and Rasmussen explored alternate methods to "precipitate" herpes leading them to favor HSV latency occurs in the skin. Of many methods tried, only intramuscular injections of adrenalin "precipitated" encephalitis (Schmidt and Rasmussen, 1960). Encephalomyelitis was "precipitated" in $60 \%$ of the rabbits given intramuscular adrenalin injections and, importantly, herpesvirus was detected in all six of these rabbit brains. A few years earlier at the Wisconsin meeting on Latency and Masking in Viral and Rickettsial Infections (Andrewes, 1957), six types of "latent" infections were described. Herpes was thought to be a unique agent because it could not be cultured from skin between episodes. Herpes latency was defined as the period of time in which skin was negative between outbreaks. Rasmussen speculated "that temporary vasoconstriction resulting from increased adrenalin output, could produce a local anoxia \{e.g. local reducing conditions\} in the skin and consequent 'reactivation' of residual herpesvirus" (Schmidt and Rasmussen, 1960). This hypothesis harkened back to the early observations of Perdrau. Early virologists stored their virus stocks as bits of infected rabbit brains in glycerin in ice boxes. Exclusion of air greatly increased the time such a stock remained 
infectious. Perdrau discovered that oxidation destroyed herpesvirus activity, but the virus stocks could be "reactivated" by subsequent reduction (Perdrau, 1931).

Rasmussen replaced the commonly employed term "precipitate" with "reactivate" directing thought toward the concept that an active agent has been muted to a latent agent, pre-existing in toto, that is somehow reactivated (presumably by reducing conditions in vasoconstricted skin) to become infectious. Latent herpes was thought by most to be present in the skin and this was an early example of a "skin trigger" hypothesis: an idea that has recently regained some attention and is further discussed below.

The early neural work by Goodpasture was supported by the formation of cutaneous herpes lesions following surgery in the trigeminal nerve tract. For example Carton and Kilbourne noted that within a few days after section (axotomy) of the fifth cranial nerve, oral or facial lesions occurred in $90 \%$ of patients if the ganglion and nerve were not destroyed (Carton and Kilbourne, 1952). The existence of a dormant form of herpes in the TG was supported by the failure of several groups to isolate the infectious agent from human TG (Burnet and Williams, 1939; Carton and Kilbourne, 1952). However, observation of HSV lesions in skin following "blowout" fractures that destroyed the nerve tract innervating the site of recurrence suggested that the virus must have already been in the skin (Hoyt and Billson, 1976). We now know the complexity of innervation of the facial skin provides a plethora of alternate routes for virus transport to the skin.

HSV-2 is discovered and VZV is proposed to be a virus that goes latent in sensory ganglia

Plummer determined that there were two serotypes of herpes simplex virus (Plummer, 1964), with different biological properties (Plummer et al., 1968), and was the first to show reactivation of HSV in the peripheral nervous system (albeit in the absence of a critical control as detailed below) (Plummer et al., 1967). But, in the absence of a tractable animal model for varicella zoster virus 
$(V Z V)$ infection, the idea that zoster was the result of reactivation of latent VZV arose instead from a long-term epidemiological study (Hope-Simpson, 1965). Formal proof that the same strain of VZV could cause both chickenpox and, subsequently, shingles in the same patient was obtained 20 years later (Straus et al., 1984)

While HSV had been isolated from skin, saliva, tears and mucosal surfaces (especially genital mucosa) by many different groups in the absence of frank lesions, the source of this virus was unknown (reviewed in (Stevens, 1975a, b)). Transplantation of facial skin from sites where lesions occurred to other parts of the body did not result in virus recurrence at those sites, and most efforts to isolate virus from such skin either directly or following explant into culture failed (reviewed in (Finlay and MacCallim, 1940; Hill, 1985)). Notably, in the absence of lesions, very low titers are usually found (Agyemang et al., 2018). And yet, viral DNA is detectable by PCR in genital swabs much more frequently than is infectious virus as discussed below. A potential role for extraneuronal sites of HSV latency in these phenomena should not be discounted.

During the 1950 s to late 1960 s laboratory animal models of herpetic disease were further developed, notably in rabbits, guinea pigs, and mice. The use of these models has led to several seminal observations, including the discovery that the two serotypes of HSV (HSV1 and HSV2) caused different pathologies in mice (e.g. HSV-2 is much more virulent than HSV-1 and causes larger pox (plaques) on liver following intraperitoneal injection) (Plummer, 1964; Plummer et al., 1974; Plummer et al., 1968). In 1970 the first experimental evidence that HSV2 remained in neural tissues for many months was presented. HSV2 was isolated in vivo after adrenalin injection, and also by cultivation of trypsinized rabbit neural tissue with indicator cells that presumably resulted from reactivation in vitro (Plummer et al., 1970).

What is the cellular site of HSV latency and reactivation?

Cook and Stevens confirmed and extended the observation that HSV remained latent in neural tissues by developing a method to reactivate HSV-1 
from dorsal root ganglia (DRG) of mice infected via the rear footpad. Following infection, virus could be isolated from feet, the PNS, and CNS with replication ceasing about 8 days post infection (dpi). Thirty dpi DRG were either excised and homogenized immediately, or explanted and co-cultivated on monolayers of susceptible cells. Infectious virus was not detected in DRG that were directly homogenized, but virus was produced by the great majority of explanted ganglia 7 to 14 days post explant. This report is often considered the first definitive proof that HSV resides within sensory ganglia in a non-infectious or latent state and is reactivated following the stress of axotomy and explant into culture (Stevens and Cook, 1971). Numerous groups subsequently applied this approach to diverse human tissues and detected reactivated HSV1 in sensory and autonomic ganglia (Baringer and Swoveland, 1973; Bastian et al., 1972; Plummer, 1973).

Stevens and colleagues went on to show that latent HSV1 could be reactivated only from central and peripheral neural tissues, including the adrenal medulla, following intravenous injection of virus to induce an artificial viremia. This solidified the idea that nervous tissues are the predominant sites of HSV1 latency (Cook and Stevens, 1976). This group also sought to demonstrate that the sensory neuron was the site of viral reactivation that led to skin lesions through the use of immunohistochemical and electron microscopic techniques (Cook et al., 1974), but their data cannot be unambiguously interpreted since tissue was examined at 48 hours and later following axotomy, a time now known to be confounded by secondary spread of reactivated virus within the explanted ganglia. The virus could have reactivated in cells other than neurons and then spread to them. The earliest solid evidence for virus reactivation in neurons was provided by the studies McLennan and Darby who employed temperature sensitive (ts) mutants in mice. At a core body temperature of 38.5 degrees, replication of the ts mutants was restricted and viral proteins in mice in which nerves were resected to induce reactivation in vivo were confined to neurons (McLennan and Darby, 1980). These neurons "appeared" to die. 
Are any essential viral gene products required for the establishment or maintenance of latency?

Watson et al. and Lofgren et al. explored whether viral proteins essential for the viral lytic cycle were required for the establishment of latency by intracranially inoculating mice with ts viral mutants and asking if the mutants could later be reactivated from brain tissue at the permissive temperature in vitro (Lofgren et al., 1977; Watson et al., 1980). The major viral immediate early transactivator ICP4 was initially thought to be essential for latency establishment, a hypothesis disproved much later by Stevens (Sedarati et al., 1993). Therefore, even viral proteins essential for viral replication like ICP4 are not absolutely required for the establishment or maintenance of latency.

Is the latent HSV genome integrated into the host genome?

Alpha herpesvirus genomes are linear double-stranded DNA that circularize upon entry into the nucleus (Sheldrick and Berthelot, 1975). The physical state of the viral genome during latency was the subject of much speculation. Fraser and colleagues first demonstrated "endless" HSV DNA in latently infected mouse brain tissue by restriction endonuclease digestion and Southern blotting. Later, this and other groups confirmed that circularized genomes are also the predominant form found in latently-infected mouse TG (Efstathiou et al., 1986; Fraser et al., 1981; Rock and Fraser, 1983). We now know that the great majority of HSV and other human alpha herpesvirus latent genomes exist as extra-chromosomal circular episomes (Azarkh et al., 2010). While integration events cannot be ruled out, they are not thought to be biologically relevant. Curiously, pseudorabies virus (PRV), an alpha herpesvirus of swine, is reported to persist largely in a linear form along with some circularized genomes (Rziha et al., 1986).

\section{Spontaneous reactivation from latency in mice}

$\mathrm{HSV}$ is commonly stated to not spontaneously reactivate in the mouse. This misconception is argued against by the consistent levels of spontaneous reactivation that have been reported for over three decades. In the late $70 \mathrm{~s}$ and early $80 \mathrm{~s}$, Hill and Blyth developed an informative model of in vivo 
reactivation, recurrence, and recurrent disease (recrudescence) in mice. Infection of the mouse ear pinna resulted in latent infections in superior cervical ganglia (SCG) that could be reactivated by diverse stimuli including UV light, DMSO on the pinna, or stripping of the pinna with cellophane tape (Hill et al., 1975). In this model, virus could be routinely isolated from the pinna in about $10 \%$ of the animals on any given day, consistent with later estimates of spontaneous productive reactivation seen within mouse TG (Blyth et al., 1984; Blyth et al., 1981). They showed that some procedures to induce in vivo reactivation resulted in detectable virus within ganglia and in skin with no evidence of recurrent disease, whereas other procedures induced virus reactivation within ganglia and recurrent lesions that contained infectious virus. This led them to postulate that there were "ganglionic triggers" and "skin triggers", the latter leading to recurrent lesions with the possible involvement of prostaglandins (known to enhance the replication of HSV in cultured cells), which were found to be elevated in the skin selectively by "skin triggers" and not "ganglionic triggers" (Harbour et al., 1978; Harbour et al., 1977), for review see (Hill, 1985). This hypothesis may still be relevant today as it might explain why infectious virus, and more frequently viral DNA, can be detected in the absence of a frank lesion.

The development of a sensitive procedure to detect viral protein expression in the whole ganglion allowed extensive analysis of latently infected ganglia for the expression of viral proteins at a single cell level (Sawtell, 2003). Whole ganglion IHC (WGIHC) allowed for detection of single neurons positive for viral proteins. A comprehensive long-term study revealed that in mice, as in humans (Agyemang et al., 2018), the frequency of spontaneous HSV reactivation (based on detection of TG neurons positive for infectious virus and viral proteins) declined during the time period between 15 and 40 days and then remained stable over the 240 days examined (Sawtell, 2003). The frequency of spontaneous reactivation in the TG was similar to the frequency observed in SCG, which also corresponded to the frequency of spontaneously positive mouse ear pinnas as reported by Hill and colleagues (Blyth et al., 1981) (reviewed in (Hill, 1985)). Analyzing sectioned ganglia for HSV proteins, 
Feldman et al. similarly found that $10 \%$ of mouse TG pairs contained neurons positive for HSV proteins and called this "molecular reactivation" (Feldman et al., 2002). Later, the same group determined that $10 \%$ of unstressed mice were positive for infectious virus in TG (Margolis et al., 2007) demonstrating that molecular reactivation is consistent with the well-recognized spontaneous reactivation rate of mice as previously reported by others. This rate is likely dependent upon the viral strain, latent reservoir, and mouse strain. The animal models noted for spontaneous reactivation, rabbit and guinea pig, also have a time-dependent reduction in the frequency of reactivation, with the highest rate of spontaneous reactivation observed being 20-35 dpi. In rabbits, reactivation is quantified by virus shedding in tear films. The source of this virus is not known but thought to be neurons in TG. In guinea pigs, vaginal lesions are scored as reactivation events. Viral DNA can be recovered from these lesions (Roizman et al., 2013). Thus, spontaneous reactivation of HSV occurs in diverse animal models including mice, rabbits and guinea pigs.

The timing of viral reactivation in neurons in vitro or in vivo following stress.

The kinetics of induced reactivation, both in vivo and in explanted ganglia, remained a major gap in our understanding of alpha herpesvirus infections. Although knowing when a triggering event occurred that resulted in spontaneous reactivation is not possible, an increased frequency of ocular shedding occurred in rabbits over a period of two weeks following a three-day procedure of iontophoresis of epinephrine into corneas to induce reactivation (presumably initiated in the innervating neurons) (Toma et al., 2008). Likewise reactivation in explanted ganglia was thought to take several days or even weeks (Stevens, 1975a). However, the rate of reactivation was faster in subsequent studies. While a variety of stimuli caused virus reactivation and spread to the mouse ear pinna in 3 to 5 days, Harbour et al. found that virus could be isolated from a few SCG as early as one day post treatment (Harbour et al., 1983). Furthermore, using a mouse model of in vivo HSV1 reactivation induced by a 10 minute hyperthermic stress (42.5 C), virus was detected in TGs of mice as early as $14 \mathrm{hrs}$ with $70 \%$ of mice positive by $22 \mathrm{hrs}$ (Sawtell and Thompson, 1992a) (reviewed in (Webre et al., 2012)). 
The same timing of primary reactivation events is evident in axotomized and explanted TG with virus being detectable by 14 hours post explant. However, unlike the in vivo situation where virus does not spread from the original reactivating neurons, virus rapidly spreads within the explanted ganglia (Doll and Sawtell, 2017; Pesola et al., 2005; Sawtell and Thompson, 2004). The potential for reactivation to occur in explants within $14 \mathrm{hrs}$ and the rapid spread of virus within the ganglion is inconsistent with conclusions drawn from earlier studies that reactivation requires several days to occur in explanted sensory ganglia. However, it should be noted that many factors could affect the levels of latency established in animal models and in turn the subsequent frequency and perhaps timing of viral reactivation in vitro and in vivo. These parameters include the method of inoculation, the virus inoculation titer, the strain of virus employed, and strain of animals employed.

\section{What is the role of the immune system in maintaining latency?}

As is the case today, the role of the host immune system in alpha herpesvirus latency and reactivation was of great interest to investigators. However, immunosuppression of latently infected mice failed to induce reactivation or produce recurrent disease (Blyth et al., 1981; Hurd and Robinson, 1977; Stevens and Cook, 1973), with only a low incidence of recurrence in hairless mice treated with the immunosuppressant drug, prednisone, being observed (Underwood and Weed, 1974). Conflicting with these findings is the more recent hypothesis that CD8 T-cells directed against a specific epitope on glycoprotein B may play a role in the maintenance of HSV1 latency (Bourne et al., 2018; Held and Derfuss, 2011; Knickelbein et al., 2008; Lahmidi et al., 2017; Liu et al., 2000; Treat et al., 2017). In contrast to HSV, depletion of CD4 cells induced reactivation of simian varicella virus in Rhesus Macaques (Traina-Dorge et al., 2019). The role of the host immune system in HSV and VZV latency and reactivation (Gershon et al., 2015) is a topic worthy of a its own review article and is not covered in further depth here. 
In vitro primary neuronal quiescence/latency and the NGF depletion reactivation model

The application of cultured primary neuron models of HSV latency led to several new concepts in reactivation. Establishment of a quiescent/latent like state in cells including neurons requires the use of antiviral compounds, or the use of replication deficient viral mutants (Harris and Preston, 1991; O'Neill et al., 1972; Wilcox and Johnson, 1987). During the late 1980s Wilcox and colleagues developed an in vitro model of HSV latency in cultured primary neurons. Quiescent/latent infections were established by infecting the neurons at very low $\mathrm{MOI}$ and maintaining them in the presence of human IgG (which contains significant amounts of anti-HSV antibodies). The antibodies were removed after fourteen days and the cultures remained latently infected for at least five weeks. These autonomic neurons derived from SCG were dependent on nerve growth factor (NGF) for their survival and deprivation of NGF (by anti-NGF antibody depletion) resulted in reactivation of latent virus (Wilcox and Johnson, 1987; Wilcox et al., 1990). These cultures were interesting in that they mimicked some of what was known about latency in vivo, including expression of the LATs (stable LAT introns) in a subset of neurons (Doerig et al., 1991). However, they did not parallel the in vivo situation in all cases. For example, thymidine kinase negative mutants established latency and reactivated within these cultures (Wilcox et al., 1992), which is not the case for either in vivo reactivation in mice, or reactivation in explanted latently-infected mouse ganglia (Field et al., 1982; Field et al., 1979; Field and Wildy, 1978; Pyles and Thompson, 1994b). Reactivation in these cultures could be induced by cyclic AMP repressors and was dependent on caspase three (Hunsperger and Wilcox, 2003). This model was eventually abandoned in part because latent infections (identified by LATs expression) and reactivation was rare at the cellular level and it was not thought likely that widespread death of neurons caused by NGF deprivation would be relevant biologically except with a few exceptions such as nerve resection caused by "blowout" fractures or surgery (Hunsperger and Wilcox, 2003). 
A resurgence of similar in vitro models of HSV latency are the topic of recent reviews (Bloom, 2016; Thellman and Triezenberg, 2017) and new in vitro models of VZV latency are under development (Baird et al., 2019; Depledge et al., 2018b; Laemmle et al., 2019). The ability to differentiate pluripotent human embryonic stem cells into neurons is being exploited to investigate latency and reactivation of HSV and VZV (for example see (D'Aiuto et al., 2019; Kurapati et al., 2017; Markus et al., 2015; Pourchet et al., 2017; Sadaoka et al., 2018)). Rodent fetal and adult neuronal culture models are also being used and are discussed further below.

\section{Using molecular approaches to address fundamental questions}

Discovery of the latency-associated transcripts (LATS) or latency related RNAs (LRRs)

There was great interest in determining whether any viral gene expression was required to maintain latency. The first report of abundant RNA transcription during HSV latency in neurons was published by Tenser and colleagues. However, the entire viral genome was employed as a probe and so the genomic location of this transcription was not known (Tenser et al., 1982). In 1986 two abstracts describing significant RNA transcription from the terminal repeat of HSV-1 during latency were submitted to the $11^{\text {th }}$ annual International Herpesvirus Workshop. Stevens and colleagues described the transcription of ICPO during latency but employed a double stranded probe. Rock and Nesburn also detected transcription but from the strand opposite of that of ICP0. Stevens et al. became aware of Rock's strand specific finding, confirmed that the transcription they detected was from the strand opposite of that of ICPO and first described the latency associated transcripts (LATs) (Stevens et al., 1987). Arguably, credit for this discovery might be shared.

The discovery of the LATs led to speculation that they might encode a protein or a function important for the establishment, maintenance and/or reactivation of latent infections. However, the earliest reports suggested that the LATs played no role in the establishment or reactivation of HSV latency (Sedarati et al., 1989) (reviewed in (Fraser et al., 1992)). Subsequent early studies led to 
confusion and controversy, largely due to the complex nature of transcription from this region that was not appreciated at the time. We now know that long, short, and micro non-coding RNAs from both DNA strands as well as unusually stable introns are generated from the LAT locus, and that most of these can be detected during both latency and during acute viral replication. Presumably expression of the LATs introns and miRNAs during the lytic cycle are the result of read through transcription late in the infection cycle. Activity from the LAT promoter is restricted during acute infection (Batchelor and O'Hare, 1990). Additionally, there are reports noting potential open reading frames (ORFs) in some of these RNAs (Bloom et al., 1996; Thomas et al., 1999; Thomas et al., 2002), but no latency related protein has yet been convincingly described. In contrast, the recently discovered VZV LAT RNA does encode a protein (Depledge et al., 2018a). The role of the LAT locus will be discussed in greater detail below.

Quantification of the number of genomes in the latently infected ganglion by the polymerase chain reaction (PCR)

Katz et al. first employed PCR to detect latent viral genomes, which laid the groundwork for the use of qPCR to address questions in HSV latency (Katz et al., 1990). These investigators confirmed the early finding of Stevens and colleagues that latent infections in sensory neurons could be established even with HSV mutants that did not replicate efficiently, including TK- and ICP4deficient mutants, and added to this list mutants lacking ribonucleotide reductase, ICP27, and DNA polymerase (Katz et al., 1990; Lofgren et al., 1977; Watson et al., 1980). More startling was the high numbers of viral genomes Katz et al. detected in latently infected ganglia (Katz et al., 1990). While many groups had observed only a few to several hundred neurons expressing LATs, PCR detected hundreds of thousands to millions of viral genomes (reviewed in (Phelan et al., 2017)). This suggests that either neurons contain multiple copies of the viral genome or that many neurons harboring latent genomes do not express detectable LATs, or both. We now know that there are 1,000 s of latently infected neurons in the TGs of mice and humans, each containing 10-100s of viral genomes and most of these do not express 
detectable LAT stable introns. (Sawtell, 1997, 1998; Sawtell et al., 2001; Wang et al., 2005b).

How many genomes are in individual latently infected neurons? Latency at the single neuron level

While the qPCR method provided unprecedented sensitivity for detecting and quantifying viral genomes in latently infected TG, methods to examine viral DNA in single cells were needed to address outstanding questions. For example, how many neurons were latently infected, were other cells also harboring viral genomes, how many viral genomes were within individual latently infected neurons, and was this genome number uniform or variable? Towards that goal, an approach termed contextual analysis (CXA) was develop. TGs were perfusion-fixed to stop all metabolic processes and to preserve DNA, RNA and protein, and the cells were dissociated and purified on Percoll gradients. Following treatment with DNase linked to beads to remove DNA from the outside of the cells, the intracellular viral genome content of individual neurons and other cells was analyzed by qPCR. Viral genomes were detected in about $1 / 4^{\text {th }}$ of the neurons, only in neurons and with copy numbers ranging from $\sim 1$ to $>10,000$ (Sawtell, 1997). Similar percentages of positive neurons and ranges of viral genome copies were later detected in human TG neurons using laser capture technologies combined with qPCR (Wang et al., 2005b). Other single-cell approaches addressing these questions were applied to VZV in human TG (LaGuardia et al., 1999; Levin et al., 2003).

The viral genome copy number in individual latently-infected neurons varies across HSV1 strains (Sawtell et al., 1998). Neurons latently infected with the virulent HSV1 strains McKrae or 17Syn+ contained an average of $81 \pm 36$ or $50 \pm 12$ genome copies, respectively. However, neurons latently infected with the avirulent strain KOS contained only $7 \pm 2$ viral genome copies, which may explain why it reactivates less well than the other strains (Sawtell et al., 1998). Yet, the percentage of latently infected neurons was similar with all three strains, varying between 26 and $32 \%$. The reason for the low genome copy 
number in KOS latently-infected TG neurons is not known but may be a reflection of the mutations in the KOS strain that disrupt the US9 gene TATA box, truncate US9 at aa58, and eliminate the native stop codon of pUS8A (Negatsch et al., 2011). pUS9 is required for efficient anterograde axonal transport (Howard et al., 2013), and pUS8A is a neurovirulence factor (Kato et al., 2016). Thus, the multiple "round trips" of virus from the body surface to nerve cells and back again, which contributes to the higher viral genome copy number latency (Thompson and Sawtell, 2000), may not occur with the HSV1 KOS strain and its derivatives.

Do any viral proteins enhance the establishment of latency?

A number of viral genes contribute to the efficiency with which latency is established. However, many of these are required for efficient lytic replication at body surfaces or in the nervous system. Surface replication efficiency is correlated with the number of latent sites established and, therefore, viral proteins important for lytic replication such as thymidine kinase appear to increase latent infections indirectly (Katz et al., 1990; Thompson and Sawtell, 2000). Other virally-encoded enzymatic functions such as dUTPase and uracil glycosylase enhanced establishment of latency and reactivation frequency likely by promoting replication within the trigeminal ganglia (TG) (Pyles et al., 1992; Pyles and Thompson, 1994a). The lack of these enzymes may also have led to a higher mutation frequency in the latent viral genomes that could exert a deleterious effect on reactivation from latency (Pyles and Thompson, 1994b). In aggregate these and similar studies on diverse viral proteins (i.e. TK, ribonucleotide reductase, virion host shut off, and various glycoproteins) demonstrate that no viral proteins are absolutely essential for the establishment of latency (Aggarwal et al., 2012; Diefenbach et al., 2008; Field et al., 1982; Field and Wildy, 1978; Izumi and Stevens, 1990; Jacobson et al., 1989; Johnson et al., 1986; Lam et al., 1996; Meignier et al., 1988; Smith, 2012; Strelow and Leib, 1995; Wang et al., 2005a; Wang et al., 2010). However, all viral proteins likely contribute to the efficiency with which latency is established indirectly by enhancing virus replication at body surfaces and in the nervous system. 
Viral lytic gene transcripts are present in latently infected ganglia in the absence of detectable reactivation

In a landmark study, Kramer and Coen found transcripts for ICP4 and TK in latently infected mouse TG. Quantification of these transcripts revealed that they were present at extremely low levels. These transcripts did not necessarily initiate at recognized promoters and may have been the products of random transcriptional activity (Kramer and Coen, 1995). Thompson and Sawtell also reported RNAs related to ICP4, ICP0, ICP22, ICP27 and ICP47 in TG latently infected with HSV1. Transcription was found upstream of normal mRNA initiation sites. Furthermore, the ICPO transcripts were not spliced as is the case during productive infection, again suggesting these might not be properly processed mRNAs, but rather random transcriptional events (Thompson and Sawtell, 2006). The presence of HSV related RNAs during latency has complicated the interpretation of results that utilize viral transcriptional activity as a marker of reactivation. This is especially true in vivo where reactivation occurs in only one or a very few neurons per ganglion and the neuronal distribution of the RNAs detected is not known. Sensitive whole ganglion approaches to detect viral transcription at the single neuron level during latency and in vivo reactivation are needed.

\section{In depth considerations of latency models and mechanisms}

The role of VP16 transactivation function in the switch between latent and lytic infection

Virion protein 16 (VP16, $\alpha$-TIF, pUL48) is produced as a leaky late protein and is packaged into the viral tegument. Upon viral fusion into cultured cells and concomitant loss of the envelope, VP16 is released from the nucleocapsid/ tegument and is thought to complex with the host cell factor 1 (HCF-1) in the cytosol. The HCF-1/VP16 dimer is transported into the nucleus where it forms the trimeric VP16-induced complex (VIC) with Octamer-binding protein-1 (Oct-1). The VIC binds to the consensus sequences, TAATGARAT, which are present in the promoters of the five immediate early (IE) genes of HSV. The acidic carboxy terminal domain of VP16 is a strong transcriptional activator, 
which then initiates the virus lytic gene transcription program by transactivating the IE genes (Ace et al., 1988; Campbell et al., 1984; Kristie and Roizman, 1987; Mackem and Roizman, 1982; O'Hare, 1993), reviewed in (Wysocka and Herr, 2003). The importance of VP16 in initiating the viral lytic cycle is revealed at low moi. In its absence, entry into the lytic cycle (plaquing efficiency) is reduced 100 to 1,000-fold (Ace et al., 1989; Smiley and Duncan, 1997).

Based on what is known about the critical role played by VP16 in initiation of the viral lytic cycle at low moi, its absence or presence would also be expected to play central roles in the establishment of, or reactivation from latency. Indeed, in cultured neurons, VP16 deposited into axons as part of the tegument complex is not transported retrograde to the neural soma with the nucleocapsid, and in the absence of its delivery to neuronal nuclei latency establishment may be favored (Aggarwal et al., 2012; Antinone and Smith, 2010). Importantly, cultured neurons infected via axons favors the entry of virus into a quiescent/latent state (Hafezi et al., 2012) and the addition of pseudorabies virus tegument proteins to the neuronal soma can shift the outcome to the lytic cycle (Koyuncu et al., 2017), a result similar to early studies of HSV light particles containing tegument proteins including VP16 (Dargan et al., 1995). As discussed further below, VP16 and its unique regulation as a pre immediate early gene in neurons orchestrates the choice between lytic and latent viral programs.

The generation of a transactivation-deficient mutant (VP16TF), in1814, provided the critical tool needed to test the role of VP16TF during latency and reactivation (Ace et al., 1989). This mutant contains a 12 bp insertion at aa379 in VP16 that retains the protein's essential contribution to virion structure but selectively disrupts the interaction of VP16 with Oct-1, thus preventing the formation of the VIC (Ace et al., 1988; Ace et al., 1989; Campbell et al., 1984; Wysocka and Herr, 2003). This and other VP16TF mutants are severely deficient in replication at low moi (McFarlane et al., 1992; Preston and McFarlane, 1998; Smiley and Duncan, 1997). Despite this, in1814 establishes latent infections in mice and subsequently reactivates with wild type kinetics 
from latently-infected ganglia explanted into culture (Steiner et al., 1990). Moreover, attempts to artificially-induce the expression of VP16 in vivo did not disrupt the balance between latent and lytic infection (Sears et al., 1991). These two influential reports seemingly disproved the hypothesis that VP16 played an important role in regulating HSV latency and reactivation.

However, whether the VP16TF studies truly ruled out an initiating role of VP16 in reactivation requires a nuanced consideration of experimental design and interpretation. First, the method used to evaluate reactivation is a central factor. The most widely used approach to evaluate the ability of latent virus within a ganglion to produce infectious virus is to dissect the infected animal, sever the ganglionic neurons by axotomy, and explant the ganglion into culture (Stevens and Cook, 1971), sometimes also dissociating or mincing the ganglion prior to explantation (Blyth et al., 1981; Leib et al., 1989a; Nicholls and Blyth, 1989). Using this method, virus was detected five to ten days post explant, which was not different than the five to six days required for wildtype and rescued virus reactivation (Steiner et al., 1990). At the time, these studies and others led to the conclusion that VP16 transactivation was not involved in reactivation from latency, and as a consequence the IE protein ICPO superseded VP16 as the major contender for this important role. However, whether explant-based reactivation accurately models in vivo reactivation is an important consideration (Sawtell and Thompson, 2004; Thompson et al., 2009).

Although there is general consensus that ICPO is required for efficient reactivation from latency. In vivo, ICPO is required for efficient viral replication and establishment of latency (Cai et al., 1993; Cai and Schaffer, 1992; Everett, 2000; Halford and Schaffer, 2001; Leib et al., 1989b), and ectopic expression of ICPO can disrupt latency in explanted ganglion neurons (Halford et al., 2001). The intersection of latency establishment levels and reactivation efficiency have clouded the issue but it is clear that at equivalent levels of latency (number of neurons and copy number profile), ICPO null mutants enter the lytic cycle (based on viral protein expression) but do not generate 
detectable levels of infectious virus (Thompson and Sawtell, 2006). Thus, while ICPO is essential for amplification of infectious virus production during reactivation in vivo this protein is not required, and appears to play no major direct role, in the initiation of reactivation in vivo.

Whether the contribution of ICPO is to the initiation or progression of reactivation may seem to be a hairsplitting issue, but as discussed above the goal of these studies is to identify the interfaces between the critical host cell factors and their mechanisms of regulating essential viral functions. An early effort to achieve this used a viral mutant, $\triangle T F I$, that was designed to gain insight into the role of cis-acting sequences in the ICPO promoter that potentially regulate ICPO expression during acute infection, establishment of latency, and reactivation (Davido and Leib, 1996). A deletion removed a number of sites in the proximal ICP0 promoter including Sp1, NF-kB, C/EBP, F2, and four TAATGARAT motifs. Strikingly, although there were reduced levels of ICPO protein expression at early times post-infection in Vero cells and in vivo, and reduced levels of blepharitis in CD1 mice and death in SCID mice, neither establishment of latency nor explant reactivation were different from the wild type or the marker rescue viruses (Davido and Leib, 1996).

Our group was also focused on ICPO and its role in reactivation, but we were utilizing an in vivo reactivation model triggered by hyperthermic stress to the intact animal (Sawtell and Thompson, 1992b). Whether reactivation in vivo was different than explant reactivation was of great interest. Remarkably, in1814 failed to reactivate and reactivation of $\triangle T F I$ was greatly reduced compared to wild type or marker rescue viruses in vivo (Thompson and Sawtell, 2006) (Thompson et al., 2009). Importantly, viral genome copy number and the number of latently infected neurons were not different, ruling out the possibility that the establishment of latency by in1814 and $\Delta T F I$ were reduced in this model. These studies revealed for the first time that reactivation in the in vivo context may have distinct constraints, which are relaxed in the explant setting. 
These studies also suggested that the TAATGARAT motifs in the ICPO promoter might be important in regulating reactivation in vivo. Specific restoration of a single TATA box proximal TAATGARAT element to the ICPO promoter in $\triangle T F I$ restored wild type in vivo reactivation frequency, emphasizing the importance of VP16 interaction at TAATGARAT elements for the regulation of ICPO expression during in vivo reactivation (Thompson and Sawtell, 2006). It was not yet clear if reactivation of the VP16TF mutant was actually blocked, or whether in1814 did reactivate and was not detected because of the $\sim 100$ fold reduced plaquing efficiency of the mutant (Ace et al., 1989). Even with wild type virus the levels of virus recovered from a reactivation event in vivo are low, and virus does not spread within the ganglion during in vivo reactivation as it does during explant induced reactivation (Doll and Sawtell, 2017). Thus, reactivation of in1814 in vivo may have occurred without being detected. This was tested by the inclusion of hexamethylene bisacetamide (HMBA), a cyto-differentiating agent used to complement the plaquing deficiency of in1814 (Ace et al., 1989), in the assays, reactivation in vivo (infectious virus production) was not detected in assays in the presence of HMBA.

We hypothesized that some yet unknown regulatory mechanism altered the normally leaky late expression of VP16 to that of a pre-immediate early gene in a neuron destined to reactivate, thereby permitting it to coordinate the expression of the five important IE genes and initiate the lytic cascade (Thompson et al., 2009). If this were the case, then in contrast to $\triangle T F I$, in which viral proteins were expressed in neurons "starting" to reactivate, neurons expressing viral proteins in in1814 infected TG would be absent following stress. Using a whole ganglion approach that allows quantification of viral protein expression at the individual neuron level, the lack of neurons expressing viral proteins was confirmed (Thompson et al., 2009). This extended our understanding of the reactivation process now to include VP16 transactivation of ICPO (and presumably the other IE genes as well but this has not been directly tested) as a key and absolutely required step in the earliest stages of viral protein expression from the latent genome. Of great 
importance, mutations in the VP16 promoter, including a four base substitution in a $\mathrm{G}+\mathrm{C}$ rich region scoring as a putative overlapping Egr-1/SP1 site ablated the ability of the virus to exit the latent state (Sawtell and Thompson, 2016; Thompson et al., 2009; Thompson and Sawtell, 2019). These findings are consistent with the hypotheses that both a functional ICPO and VP16 transactivation were required for efficient virus production, but de novo preimmediate early expression of VP16 is required to initiate viral gene expression during reactivation.

Additional supporting data comes from a series of refined viral mutants containing single or double amino acid changes in the core domain critical for VIC formation (Sawtell and Thompson, 2016; Sawtell et al., 2011), including the first viral mutant to specifically disrupt the HCF-1 interaction. The in vivo reactivation phenotypes observed for these mutants align with predictions based on in vitro biochemical analyses of amino acids critical for VIC formation (Stern et al., 1989; Wysocka and Herr, 2003). Together, there is now strong evidence that VP16 interactions with Oct-1 and HCF are critical for the earliest stages for reactivation in vivo (Figure 1). That the core domain mutant phenotype was a result of a deficit in VP16 transactivation was supported further by the in vivo reactivation impairment of a mutant in which the core domain was intact, but the acidic transactivation domain (TAD) was lacking (Thompson et al., 2009). Importantly, all of these mutants reactivate following ganglion explantation, emphasizing the importance of the reactivation model used and the associated neuronal metabolic state. Efforts to develop and characterize additional in vivo reactivation triggers to ask whether hyperthermic stress is representative of other stressors (i.e., do diverse stressors flow into a common interface on the viral genome) is in progress. In vivo reactivation by additional triggers, for example, local skin trauma (see below), is dependent upon VP16 transactivation.

\section{Modeling reactivation in vitro}

The development of an in vitro latency model that provides a platform for dissecting host cell signaling pathways involved in viral genome entry into 
latency, its maintenance, and its reactivation would be a valuable resource. Ideally such models could yield hypotheses testable in the more complex in vivo setting. Defining the limitations to these models and the approaches used to probe outcomes is critical to interpreting results obtained from them.

There is a growing number of in vitro latency models for both HSV and VZV that are the topic of several recent reviews (Bloom, 2016; Depledge et al., 2018b; Thellman and Triezenberg, 2017). In vitro models have been exploited to study both the establishment of latency and subsequent reactivation of VZV. Major efforts in the use of human embryonic stem cells for the study of VZV have led to several critical improvements, including axon-restricted infection protocols and methods to obtain enriched populations of specific types of neurons (Kurapati et al., 2017; Markus et al., 2015; Pourchet et al., 2017; Sadaoka et al., 2016; Sadaoka et al., 2018). These models are being explored for HSV latency and reactivation as well (Pourchet et al., 2017) and have brought forward the concept of a two-phase paradigm of transcription leading to reactivation. It should be noted that the establishment of latency in most of these models requires the use of antiviral compounds such as acyclovir, and latency is considered to be established after just a few days. It is not yet clear how this "forced" latency parallels latency in vivo. A primary limitation of these models is the disruption of the intricate context of the neuron and the very different mode of entry of the virus into the neuron. Roizman noted that satellite cells which surround neurons and communicate constantly with them may play roles in the establishment and maintenance of latency. Also noted is the fact that the acyclovir employed to suppress virus replication does not prevent the initial stages of reactivation and in effect might serve to eliminate those neurons in which spontaneous reactivation occurs (Roizman and Whitley, 2013). Immune functions also are thought to play important roles in these processes and are absent (for review see (St Leger and Hendricks, 2011)). 
Reactivation in the superior cervical ganglion neuron culture model

As discussed above a primary SCG neuronal culture model of HSV quiescence/latency and reactivation was reported to require nerve growth factor (NGF) to maintain HSV latency/quiescence (Wilcox and Johnson, 1987, 1988; Wilcox et al., 1990). One current hypothesis is that the sustained signaling program mediated by NGF via the TrkA receptor, PI3 kinase p110a isoform, PDK1 and Akt represses HSV replication, maintaining the quiescent state (Camarena et al., 2010; Kim et al., 2012). A mutant containing a GFPUS11 fusion gene was employed so that fluorescence would mark lytic gene expression. The PI3 kinase inhibitor LY294002 was found to parallel NGF withdrawal in that the number of GFP positive wells (6 days post treatment) increased 3.5 -fold from the baseline of $20 \%$ (time 0 ) to $70 \%$ (48-72 hrs post LY294002 treatment). Switching of wells from GFP negative to positive (a surrogate for reactivation) did not occur in $30 \%$ of wells and the number of neurons expressing GFP (the marker of lytic cycle employed) averaged 5\% (48/1000) (Cliffe et al., 2015). The number of neurons containing latent viral genomes was estimated at $25-50 \%$ (stated in the discussion of (Kim et al., $2012)$ ); thus, reactivation occurs in the range of $10-20 \%$ of infected neurons. $\mathrm{PI} 3$ kinase inhibition does not induce reactivation in most of the neurons in the well that contain the viral genome.

Presumably all of these embryonic SCG express the NGF TrkA receptor, indicating that additional factors are preventing viral genome activation following inhibition of PI3 kinase. Considering reactivation at the level of the individual latently infected neuron treated with the inhibitor is actually rare, sustained signaling through PI3 kinase and Akt would not seem to be universally required to maintain latency in this culture model (Camarena et al., 2010). This model system allowed detailed analysis of the role of individual growth factors; a study not practical in the in vivo context. Interestingly, these authors demonstrated that other growth factors expressed in SCG neurons, including epidermal growth factor (EGF) and glial cell-line derived neurotropic factor (GDNF), both of which act through the PI3-kinase pathway, differed in their ability to maintain quiescence/latency in these cultures. This was based 
on the abilities of these growth factors to provide sustained signaling through PI3-K and Akt. More recently, the importance of neurotropic factors in adult sympathetic and sensory neurons was examined (Yanez et al., 2017). While NGF and GDNF withdrawal induced HSV1 reactivation in adult sympathetic neurons, in adult sensory neurons NGF deprivation had no effect. Neurturin (NTN) and GDNF withdrawal induced HSV1 and HSV2 reactivation, respectively. Thus, the nature of receptor tyrosine kinase (RTK) signaling appears to be a key host parameter that regulates the HSV1 quiescent to lytic activation in a subset of neurons even in this "homogeneous neuronal" model system. While the importance of neurotrophic factors during development is well established (Indo, 2018), in the adult nervous system a role for continuous NGF or other neurotropic support is less clear as is the relevance of neurotropic factor withdrawal as a trigger of reactivation (Skaper, 2017).

\section{A two phase VP16TF dependent HSV reactivation model}

In a second study using the SCG neuron culture model, the expression of 4-5 viral genes from IE, E, $\operatorname{Lg}_{1}, \operatorname{Lg}_{2}$ kinetic classes were profiled following LY294002 treatment (Kim et al., 2012). Two distinct phases of transcriptional activity were observed. During the first at 20-24hr (Phase I), extremely low levels of UL30 (658 RNA copies/sample*) and UL48 (3,470 RNA copies/ sample $^{*}$ transcripts were detected when protein synthesis was inhibited (cycloheximide, which blocks all protein synthesis, was added $10 \mathrm{hrs}$ after LY294002). In the absence of the protein synthesis inhibitor, neither infectious virus nor increases in viral DNA were observed during the 25hr Phase I. Phase II encompassed 48hr and onward, during which time modest replication of the viral genome (2.5 rise over baseline) and infectious virus production (250 pfu at $72 \mathrm{hrs}$ ) were detected. Thus, Phase II has the hallmarks of a lytic infection. Examination of the SCG neurons for viral protein expression during both phases included three proteins: VP16, ICP0, and ICP27. Curiously, VP16 was detected in $5 \%$ of the neurons/well at the time of LY294002 treatment, representing $10-20 \%$ of the infected neurons. Following LY294002 treatment and during Phase I, VP16-positive neurons increased 5 -fold by $20 \mathrm{hrs}$ to $25 \%$ of cells which is $50-100 \%$ of the infected neurons/well. ICP0 and ICP27 
expressing neurons were detected during Phase I but the frequency was not indicated. These proteins appear in clusters of neurons suggestive of cell to cell spread. Characterization of the spectrum of viral proteins expressed during Phase I will be important to determine. The assumption is made that the Phase I transcriptional burst is the source of the viral proteins and, furthermore, that these proteins drive the productive Phase II event. 10\%-20\% of infected neurons/well express VP16 before the transcriptional burst is induced by LY294002 treatment. Whether other proteins are present at this time is not reported but is quite important, as this may represent persistent infection.

This model includes a forced form of latency requiring suppression of viral replication by the anti-viral compound acyclovir (ACV) for a 1-week period, which is quite different than the events and time frame that occur in vivo. While it appears that the resulting cultures conform to latency as broadly defined, analysis of latent viral genomes in neurons has revealed that within a given nucleus their association with promyelocytic leukemia protein (PML) containing nuclear bodies and histone variants are features of latency. These are under investigation and likely to be important (Cohen et al., 2018; Lomonte, 2016; Maroui et al., 2016). The potential that this model is characterized by a low level of persistent infection is likely. In vivo the presence of viral protein has been examined extensively using approaches at least as sensitive as those employed in the in vitro studies. In vivo viral protein is rarely detected and, in extensive studies using wild type virus, its presence correlates with the detection of infectious virus in what are likely spontaneously reactivating neurons (Sawtell, 1998, 2003; Sawtell et al., 1999; Sawtell et al., 2001). From this perspective, neuronal cultures do not appear to model in vivo latency in TG. Even if only $0.1 \%$ of latently infected TG neurons expressed cytoplasmic VP16, these $\sim 6$ neurons would be detectable assuming similar expression levels of protein in vivo as in the cultured neurons. It is possible that host immune functions effectively "remove" these viral protein positive neurons. This is observed in vivo during the final stages of a reactivation event in reactivating neurons and late during the lytic cycle in ganglia (Doll et al., 2020; 
Goodpasture, 1929). However, if this were the case and such neurons were removed through time, a reduction in the size of the in vivo latent reservoir would be expected over time, which is not observed (Thompson and Sawtell, 2011). These differences could arise from differences between SCG and sensory neurons, and examination of latent infection and reactivation at the neuronal level in SCG in vivo may be informative.

An additional feature of the SCG neuron culture model is the hypothesis is that VP16 remains sequestered in the cytoplasm with HCF-1 until HCF-1 is transported to the nucleus, which is triggered by LY294002 treatment. Whether these HCF-1/ LY294002 studies were done in infected or uninfected cultures is difficult to interpret (Kim et al., 2012). While the HCF-1 correlation is of interest, further studies are needed to test this hypothesis. Simple colocalization studies would provide strong support for the hypothesis that VP16 is sequestered in the cytoplasm by HCF-1 and is then translocated to the nucleus by HCF following LY294002 treatment. These cultures systems are ideal for addressing this type of question. The GFP-expressing neurons would be expected to result from the nuclear translocation of VP16 by HCF-1. Drawing these relationships is especially important since infection is expected to promote cytoplasmic to nuclear translocation of HCF-1 six days prior to LY294002 treatment. During acute infection of TG in vivo, HCF-1 relocates to the nucleus in many neurons. Importantly, this nuclear translocation of HCF-1 during acute infection does not return to the pre-infection cytoplasmic localization. Thus, in a latently infected ganglia, there is a persistent high percentage of neurons in which HCF-1 is nuclear.

\section{A histone methyl/phospho switch is required for HSV reactivation}

A third study using the SCG neuronal culture model revealed novel concepts regarding the mechanism of HSV reactivation with respect to Phase I and its requirement for Phase II. The conclusions drawn from this study are that (i) a methyl/phospho switch at H3S10 during Phase I is required for HSV reactivation and that (ii) the DLK/JIP-3 JNK pathway is directly linked to this switch. While this study has the potential to be quite important in providing 
insight into the molecular signaling underlying HSV reactivation, aspects of the experimental design raise questions and emphasize the challenges faced. First, interpretation of the study relies heavily on the specificity of two inhibitors of JNK, SP 600125 and AS 601245. In an extensive evaluation of the selectivity of protein kinase inhibitors, SP 600125 was tested and 19 of the 69 protein kinases tested were inhibited with similar or greater potency than JNK isoforms (Bain et al., 2003; Bain et al., 2007; Fabian et al., 2005; Tanemura et al., 2010; Uitdehaag et al., 2012). AS 601245 was also determined not to be selective for JNK. Importantly, AS 601245 was found to be an exceptionally potent inhibitor of PIM1, PIM3 and GSK3 with $\mathrm{IC}_{50}$ values in the nanomolar range, 50-100 fold lower than the $\mathrm{IC}_{50}$ values for JNK1 and JNK2 (Bain et al., 2003). This does not mean that JNK was not inhibited in this study, but it does mean that JNK was not the only kinase inhibited. Thus, it is not possible to attribute the phenotypes observed to JNK inhibition without further studies. It is also possible that the observed effects of the inhibitor over time (Phase I 18hr) and (Phase II 72hr) are related to the inhibition of different kinases and the phenotypes observed in phase I are unrelated to phase II making interpretation of the results difficult.

A second issue arises from additional limitations of the experimental design. The viral genome related phenotypes, i.e., either transcription (ICP27 related RNA) or the histone modifications related to specific viral promoters were measured from the entire population of cells in a given well. There is no information on the distribution of these phenotypes among the many cells in the well. This is critically important because these averaged phenotypes are being connected to the very minor population of reactivating neurons in the well. Thus, while an event occurs in Phase II at 72 hrs post treatment (GFP expression in a small number of cells), whether the RNA detected in Phase I at $18 \mathrm{hrs}$ is or is not expressed in these particular cells (at $18 \mathrm{hrs}$ ) is not known. Whether the Phase I transcriptional activity has any effect on reactivation remains an open question. VP16 expression in this study was not reported but could have been informative. This becomes even more complex given that the limited number of modified histones detected cannot be ascribed to the 
transcriptional activity from any given viral promoter. The fact that GSK-J4 treated neurons during phase I showed no difference in the relative levels of ICP27 RNA in the total cell population does not mean that the distribution of the RNA did not change among individual neurons.

As mentioned, the use of inhibitors or depletion strategies to eliminate or reduce the function of key host proteins without the required supporting studies is problematic. While this type of approach can indicate the importance of that function to the reactivation process (for example GSK-J4 in explant reactivation) whether this is a direct effect (i.e. methylase function on the viral genome) or more likely, a result of effects on host cell functions that then influence reactivation is often difficult to parse out. Additional studies are required before drawing direct links between the host function and the viral genome. For reference, a more detailed comparison between the in vivo reactivation model and the SCG model with respect to latency and reactivation is shown in Figures 2 and 3.

\section{HCF-1: A potential VP16 independent inducer of reactivation}

HCF-1 is an essential transcriptional co-regulator that is important for several aspects of cell proliferation based on cell culture genetic studies (reviewed in (Minocha et al., 2016; Wysocka and Herr, 2003; Zargar and Tyagi, 2012)). HCF-1 protein is located at the transcriptional start sites of many genes (over 5400 genes in Hela cells), associating with both sequence-specific DNAbinding proteins, chromatin-modifying enzymes (Dejosez et al., 2010; Michaud et al., 2013), transcription initiation factors, and elongation complexes (Alfonso-Dunn et al., 2017). As such, HCF-1 is a scaffold protein central to normal cell function, bringing together regulatory effector proteins. As discussed above, HCF-1 was first identified as a component of the VP16 induced complex (VIC) and a similar complex Oct-1/ORF10/HCF-1 was identified for IE gene expression regulation in VZV (Narayanan et al., 2005).

The potential ability of $\mathrm{HCF}-1$ to be recruited to the viral genome through binding partners other than VP16 raises the possibility that HCF-1 could play a 
role in initiating expression of the viral IE genes apart from its interaction with VP16. This hypothesis was proposed more than a decade ago (Kristie et al., 2010; Whitlow and Kristie, 2009) and is a viable possibility during high multiplicity infection (cultured cells) or explant induced reactivation. These are both ex vivo contexts in which viral IE gene expression and viral lytic cycle entry are not dependent upon VP16 transactivation function (Ace et al., 1989; Steiner et al., 1990). However, in vivo replication in the absence of VP16 is severely impaired at peripheral sites of infection and in the nervous system (Sawtell and Thompson, 2016; Sawtell et al., 2011; Thompson et al., 2009), indicating that if HCF-1 is facilitating IE gene expression in the absence of VP16 it is quite limited in the in vivo context. Consistent with this, hyperthermic stress induced reactivation is VP16 dependent. Although the possibility that distinct triggers could interface with the viral genome in vivo in diverse ways has not been fully explored, a VP16-independent role for HCF-1 in driving IE gene expression in vivo does not currently have support. Identification of potential HCF-1 binding partner(s) that recruit HCF-1 to the latent viral genome in the absence of VP16 would support the hypothesis. However, VP16 transactivation function mutants do not express any detectable viral proteins in latently infected neurons in vivo following reactivation inducing stresses (Sawtell and Thompson, 2016; Sawtell et al., 2011; Thompson et al., 2009). This strongly suggests any such VP16 independent recruitment of HCF-1 to the latent genome does not initiate viral reactivation and detectable viral protein expression.

JQ1 and reactivation: manipulation of an epigenetic reader perturbs viral homeostasis

Epigenetic features of herpesvirus genomes, including the chromatin associated with latency and changes observed during reactivation of the alpha herpesviruses are the subject of multiple reviews (Balakrishnan and Milavetz, 2017; Lieberman, 2016). Newer findings include the role played by CTCF binding sites on the HSV genome and their cognate binding proteins to the establishment and maintenance of latent infections (Washington et al., 2018a; Washington et al., 2019). 


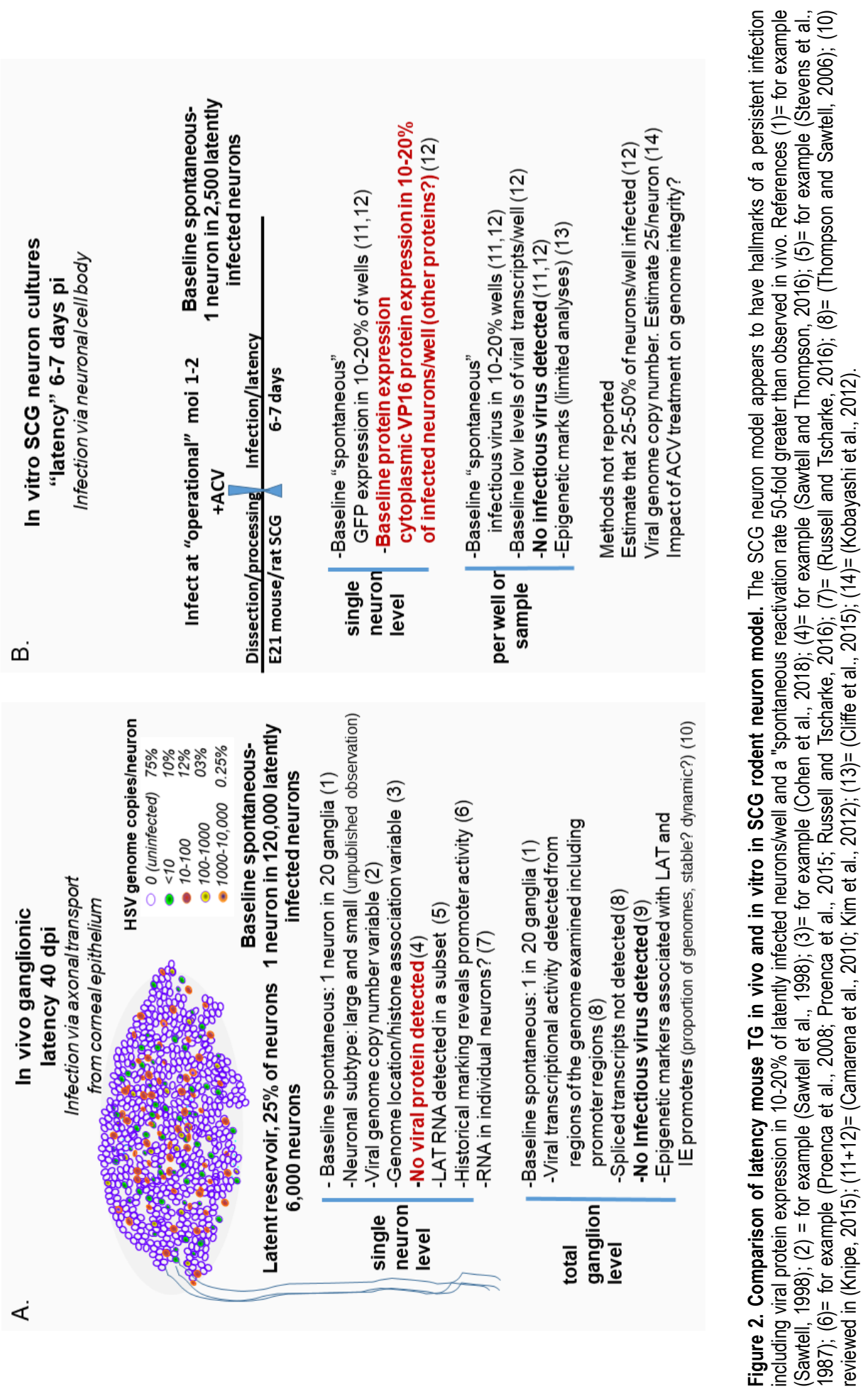



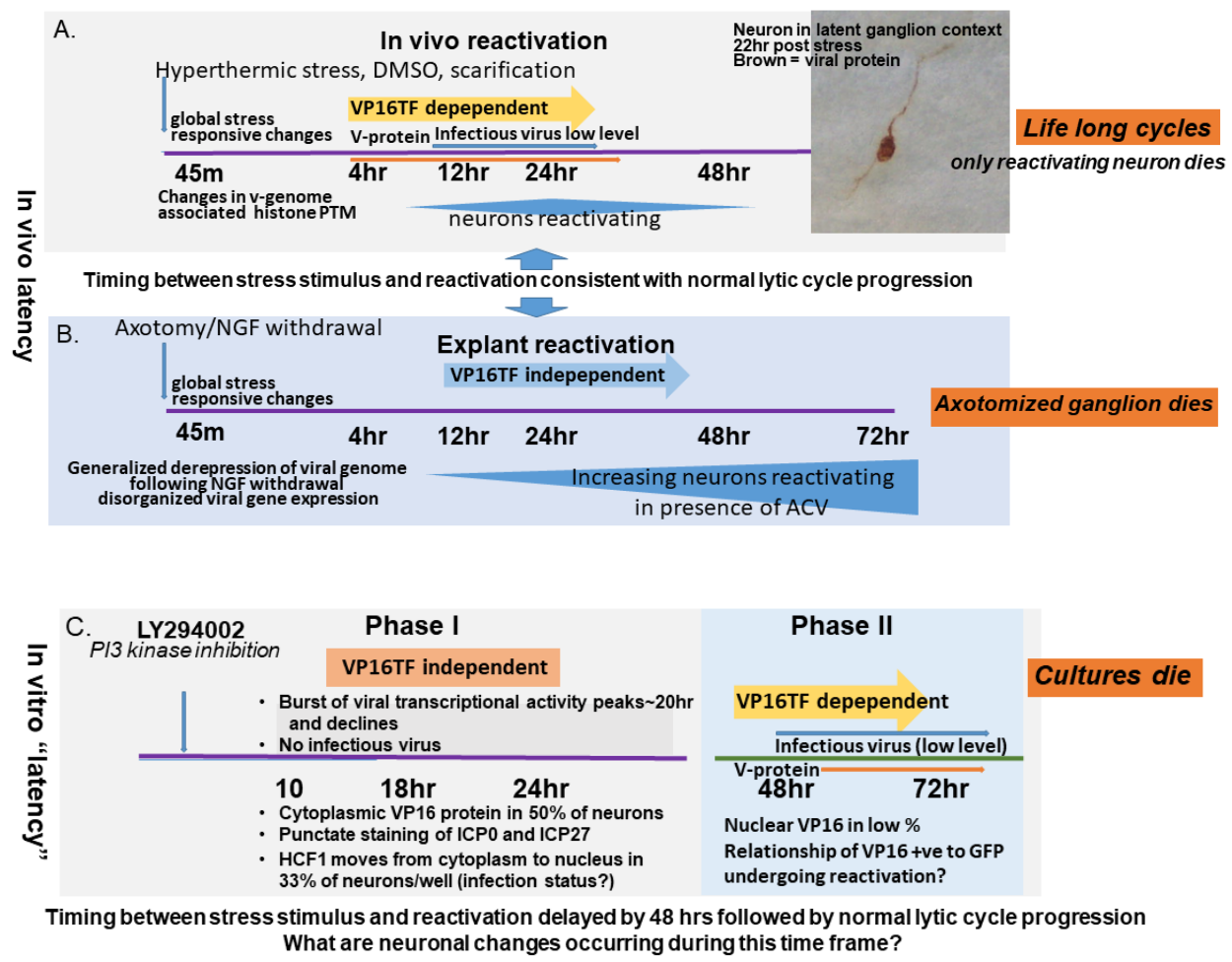

Figure 3. Comparison of the timing of reactivation in latently infected ganglia and SCG cultured neurons. Infectious virus can be detected in latently ganglia following stress in vivo (A) or axotomy (B) within $14 \mathrm{hrs}$ post stimulus. In conrast, infectious virus is not detected until $48 \mathrm{hrs}$ after PI3 kinase inhibition(C).

The availability of small molecule inhibitors of epigenetic readers and writers designed as potential cancer therapeutics have provided probes to test for effects on viral transcription and replication. An epigenetic compound library screen to test for effects on HSV replication in Vero cells revealed that BET (Bromodomain and Extraterminal Domain) protein inhibitor JQ1 increased HSV1 and 2 lytic infection by as much as 100 fold (Ren et al., 2016). This effect was specifically dependent upon the BET protein, Brd4. Paradoxically, knock down of Brd4 inhibited viral replication. The requirement for Brd4 for 
transcription, replication and other functions is reported for a number of viruses (McKinney et al., 2016; Wang et al., 2013).

Alfonso-Dunn, et al, tested the ability of JQ1 to modify explant reactivation, finding that consistent with the effect of the cyto-differentiating agent HMBA (that also inhibits Bet bromodomain proteins), JQ1 modestly increased the number of neurons expressing viral protein at $48 \mathrm{hrs}$ post explantation from 2 to 7 (Alfonso-Dunn et al., 2017). The shared function in the release of positive transcription elongation factor, P-TEFb, from the inhibitory 7SK small nuclear ribonucleoprotein (7SK snRNP) complex of the two compounds (HMBA and JQ1) and their well characterized effect on HIV latency, suggest that transient release of $\mathrm{P}$-TEFb facilitated reactivation, although further studies are required to demonstrate this (Abner et al., 2018; Bensussen et al., 2018; Khoury et al., 2018). The effect of JQ1 was also tested in vivo with latently infected mice being injected with JQ1 twice at 24-hour intervals. Increased levels of ICP27 and $\mathrm{gC}$ transcripts were detected in TG and 2-3-fold enhancement of viral DNA in some eyes were detected at $48 \mathrm{hrs}$. These findings are intriguing but in the absence of infectious virus or viral protein detection, whether these changes represent bone fide reactivation remains an open question. Nonetheless, the ability of JQ1 to perturb viral latency in vivo is significant. JQ1 is a broad BET domain inhibitor and not selective for Brd4. Thus, in the absence of additional studies, the mechanism underlying the observed phenotypes is yet to be illuminated.

Frequency of HSV2 genital shedding implies HSV2 is continuously "reactivating" in the ganglion. Corollary: the reactivating neuron must survive the production and release of infectious virus

Multiple studies have now solidified not only the shedding frequency but also the peak amounts of viral DNA and rate of decay with which HSV2 DNA is detected in human genital swabs collected from a specified regional map (Agyemang et al., 2018; Ramchandani et al., 2017; Sacks et al., 2004). These studies have substantially altered what had been established concepts of the frequency of viral presence at the genital mucosal surface and raise important 
questions regarding the transmission potential of these frequent PCR detectable shedding events. The results of these studies were best fit by a mathematical model that assumed a nearly constant release of small numbers of virions from ganglionic neurons (Schiffer et al., 2009). While a legitimate hypothesis, it is worth noting that the source of viral DNA detected by PCR in the genital swab is not known but rather assumed to be the innervating sensory ganglia. Thus, the concept is based on a mathematical model which assumes that the only source of viral DNA is (or could be) the sensory ganglion. More recent mathematical modelling from this group is focused on immune control in the mucosa (Gottlieb et al., 2017; Schiffer et al., 2018). Based on the shedding frequency, neurons presumably survive reactivation and are able to undergo repeated reactivation events; otherwise, frequent shedding cannot easily be explained. However, the ability of HSV2 to persist in other cell types is well described in the older literature, including HSV in hair follicles, skin, T cells, B cells, and myeloid cells (Al-Saadi et al., 1988; Claoue et al., 1987; Easty et al., 1987; Nicholls et al., 1996; Scriba, 1977, 1981; Shimeld et al., 1986; Shimeld et al., 1982; Tullo et al., 1985). Additionally, the idea that the reactivating neuron must survive based on this level of shedding does not appear to consider the number of ganglia that could be potentially alternate sources for the viral DNA in genital skin or mucosa. Progress in developing animal models to gain insight into the contribution of other ganglia to vaginal reactivation (Bertke et al., 2007; Lee et al., 2015; Pieknik et al., 2019; Yanez et al., 2017) as well as developing the tools in HSV2 to test hypotheses in vivo (Kawamura et al., 2018; Pieknik et al., 2018) will undoubtedly deepen current understanding of HSV1 and 2 reactivation and the distinctions between them.

A recent report detailed the resolution of reactivation of HSV1, characterizing the surrounding cellular context and morphological changes in individual neurons undergoing reactivation in vivo (Doll et al., 2020). Infectious virus was detected in a high percentage (60-80\%) of the trigeminal ganglia at 20 hours post-reactivation stimulus but declined by 48 hours post-stimulus $(0-13 \%)$. Importantly, in addition to intact viral protein positive neurons, fragmented viral 
protein positive neurons morphologically consistent with apoptotic bodies and containing cleaved caspase-3 were detected. The frequency of this fragmented phenotype increased through time post-reactivation. These fragmented neurons were surrounded by Iba1+ cells, consistent with phagocytic removal of dead neurons. Treatment with anti-CD4/CD8 depleting antibodies did not alter this outcome. In contrast, blocking viral DNA replication during reactivation prevented neuronal fragmentation within the 48-hour time frame, even though viral protein was expressed. These findings suggest that reactivation in vivo of HSV1 is resolved through the destruction of the neurons which appears to be independent of antigen-mediated $\mathrm{T}$ cell cytotoxicity but does require viral replication. Similar studies with HSV2 are needed.

\section{The role of the latency associated transcription unit (LATU) in latency and reactivation: a reexamination of what we think we know}

Functions of products from the LATU locus

As more knowledge concerning the rather subtle effects that non-coding RNAs exert on many different processes including transcription, translation, post translational modification, and chromatin structure have been described, the appearance that the non-coding RNAs generated in the LAT locus had no or minor effects on latency/reactivation can be attributed at least in part to the general lack of assays sensitive enough to measure their influences individually and in aggregate (Chen and Aravin, 2015; Dhanoa et al., 2018; He et al., 2014; Zheng et al., 2017). Space restrictions prevent presentation in detail of all of these earlier studies on the LAT locus and its functions here, and readers are directed to a recently published comprehensive review on this subject (Phelan et al., 2017). In brief, the latency associated transcript (LAT) is a $\sim 8.5 \mathrm{~kb}$ mRNA that maps largely to the long terminal repeat of the virus and is antisense to the ICPO and ICP34.5 genes (Wechsler et al., 1988). It is the only mRNA abundantly transcribed during latent infection of neurons and it expression is strongly repressed during acute infection by an ICP4 binding site that includes the transcriptional start site of LAT (Batchelor et al., 1994). The LAT mRNA is spliced, which produces two co-linear introns of 2.0 and $1.5 \mathrm{~kb}$ that share the same splice donner and acceptor sites, differing by an internal 
splice in the $5^{\prime}$ end of smaller intron (Farrell et al., 1991; Phelan et al., 2017). These introns are stable due to an unusual lariat structure that is not resolve efficiently and are partially antisense to the $3^{\prime}$ end of the ICPO mRNA and together are known as the LATs (Mukerjee et al., 2004). The LAT mRNA does not encode any known proteins and has a short half-life. It is processed by cellular mechanisms into several microRNAs and stable small RNAs, the functions of which are the subjects of current research efforts. The LAT locus is more complex, having multiple transcripts originating from both strands, none of which encode known proteins. These mRNAs are also processed into microRNAs and are expressed during lytic and latent infections at low levels. The patterns of microRNA expression and sequences from the LAT transcriptional unit locus (LATU) are not the same for HSV-1 and HSV-2. Curiously, deletion of a small $\sim 200$ bp region of the basal LAT promoter including the TATA box and mRNA start site perturbs the expression of most if not all of the transcripts originating in the LATU (Phelan et al., 2017). Thus, many of the phenotypes originally attributed to "LAT", may actually map to other nearby regions or on the strand opposite of the LAT mRNA (Phelan et al., 2017; Roizman et al., 2013).

Leib et al. provided evidence that a LAT null mutant that replicated normally in vivo displayed a reduced reactivation phenotype in a dissociated ganglia explant model. One caveat was that the slot blot analysis of latent viral genome DNA may not have been sufficiently sensitive to determine a defect in the establishment of latency by the mutant (Leib et al., 1989a). Sawtell and Thompson first determined that LAT locus mutants establish latent infection less efficiently than wild type. While the mechanism(s) involved still remain controversial, this phenotype is one that has stood the test of time and is shared among the various mouse rabbit and guinea pig models (Phelan et al., 2017; Roizman et al., 2013) (Krause et al., 1995; Perng et al., 2000b; Sawtell and Thompson, 1992a; Thompson and Sawtell, 1997, 2001).

Two important questions remained. Is the LAT locus required solely for the efficient establishment and/or maintenance of latency, or does it also exert a 
positive effect on reactivation from latency? What is the mechanism underlying the reduced establishment of latent infections and/or the increase in reactivation from latency? Answering these questions required more sensitive quantitative assays. Using a quantitative single neuron approach, it was found that fewer latent infections were established in mice infected with LAT-null mutants. When methods were employed to reach equivalent latency between wild type and mutant strains, no evidence for a specific defect in viral reactivation from latency was detected (Thompson and Sawtell, 1997). Counting the total number of neurons present in uninfected or latently infected mouse ganglia latently infected with wild type or LAT null mutants in strain 17 syn+ revealed twice the number of neurons were killed in mouse TG infected with the LAT-null mutants compared to the rescuants and wild type. Very low levels and similar numbers of neurons undergoing apoptosis were seen in both groups (Thompson and Sawtell, 2001). Whether transcription from the LATU locus exerts a negative effect on virus entry into the lytic cycle in neurons and in its absence viral lytic infection kills more neurons, or something made from the LATU protects neurons from cytopathic effects associated with HSV replication and thereby increases successful establishment and/or reactivation frequencies, is unknown. Whatever the mechanism, LATU expression reduces lytic cycle gene expression during acute infection of mouse TG neurons (Garber et al., 1997). Increased neuroinvasiveness was displayed by mutants lacking specific regions of the LAT locus (Jiang et al., 2016; Jiang et al., 2015; Thompson and Sawtell, 1997). More recent findings demonstrate that the LAT transcription program is expressed early and first in TG neurons during acute in vivo infection. Thus, LAT is expressed at a time when it could negatively influence entry into the lytic cycle in neurons. (Sawtell and Thompson, 2016).

\section{HSV LATs and neuronal apoptosis}

The hypothesis that the LAT locus protects newly infected sensory neurons from apoptosis immediately after the lytic cycle has ended in the ganglia (hypothesized to be induced as the result of toxic viral virion proteins) is steeped in the lore of HSV1 latency (Perng et al., 2000a). As recently reviewed 
this may not be true (Roizman et al., 2013). Significantly, Perng et al. reported extensive apoptosis (>25\% of neurons per section) in $66 \%$ of TG sections infected with a LAT mutant and in $4 \%$ of sections from TG infected with the rescuant or from TG of uninfected rabbits on day 7 postinfection (Perng et al., 2000a). Unfortunately, this experiment has never been repeated. A manuscript that is often cited to support the idea that the LAT locus blocks apoptosis in the mouse model actually reported very low numbers of neurons undergoing apoptosis (<0.01 to <1\%) 30 days postinfection with LAT mutants (Branco and Fraser, 2005), and the relationship of this minor amount of TUNEL staining at 30 day postinfection to the "extensive apoptosis" detected by (Henderson et al., 2004; Jin et al., 2005) and colleagues in rabbit TG only at day 7 postinfection, but not at earlier or later times is not obvious. Further studies with mutants in which anti-apoptotic proteins were inserted in place of LAT are considered to support this hypothesis (Jin et al., 2005; Perng et al., 2002). However, only the downstream phenotypes of ocular shedding (rabbit) or explant reactivation (mouse) were examined, and not the apoptosis of neurons per se. That Wechsler and colleagues were unable to demonstrate more extensive apoptosis in mouse TG infected with LAT null mutants but did find suppression of the reactivation deficient phenotype in mice suggests other mechanisms may have been responsible. The pleomorphic functions of the inserted proteins and the absence of assessment of apoptosis precludes attributing the observed effect on the inhibition of apoptosis. Further experimentation is warranted to test this hypothesis, and experimentation might be productively extended to studies in human neuronal cultures as well.

Ectopic expression of portions of the LAT locus interferes with apoptosis induced with drugs like etoposide in cultured cells (Jin et al., 2003; Peng et al., 2003). Two small non-coding RNAs from this locus can inhibit viral replication and can also cooperate to reduce apoptosis in cultured cells (Shen et al., 2009). These functions may be important during productive infection by the virus, which encodes many functions that inhibit apoptosis including ICPO, ICP34.5, gJ, gD, US3, and ribonucleotide reductase (for review see (Yu and $\mathrm{He}, 2016))$. 
The LAT locus serves to maintain latent infections

Regardless of the mechanisms involved, it is clear that the latency associated transcript locus of HSV-1 is required for long-term maintenance of reactivation competent latent infections (Thompson and Sawtell, 2011). Mice were infected with a LAT null mutant and a rescued variant maintained for 30 days post inoculation at which time were each divided into two groups. One half of the latently infected mice were maintained an additional 294 days. Additional mice from these same groups were subjected to the hyperthemic stress procedure an average of 2.5 times per week during 280 days after the initial 30-day period. After week 40 the mice receiving the multiple stress treatments were rested for two weeks, and then all of the mice were subjected to a final stress procedure to induce reactivation in vivo. Two measures were employed to quantify the outcome in TG at 22 hours post HS, (i) the quantification of infectious virus and (ii) quantification of the number of neurons exiting latency using whole ganglion immunohistochemistry (WGIHC) for viral proteins.

Does the LAT locus specifically enhance reactivation from latency in the rabbit model?

As discussed above, when the level of latency established by LAT null mutants in mouse TG is equivalent to that of wild type virus, stress induced reactivation from latency is also equivalent, and even more efficient on a per latently infected neuron basis (Thompson and Sawtell, 1997). This locus is also required for the long-term maintenance of latent infections (Thompson and Sawtell, 2011), emphasizing that in the mouse model it serves to reduce lytic infection. However in the rabbit a number of studies support the idea of a direct role for the LAT locus in promoting viral reactivation from latency (Bloom et al., 1996; Hill et al., 1990) as reviewed in (Toma et al., 2008). This may indeed be a difference between the rabbit and murine models as in the rabbit LAT locus transcription is associated with an increase in lytic gene transcripts such as ICP4, TK and gC, (Giordani et al., 2008) whereas the exact opposite, a decrease in these transcripts, was seen in the presence of an intact LAT locus (Garber et al., 1997). 
A recent report suggests LAT null mutants may have a specific reactivation deficit. Using an interesting new approach that circumvents this problem, Bloom and colleagues expressed hammerhead ribozymes directed at the $5^{\prime}$ exon of the primary LAT (or a control ribozyme) in TG neurons of rabbits latently infected with wild type HSV1. A significant reduction of induced reactivation was found in rabbits receiving the anti-LAT ribozyme (Watson et al., 2018). If this approach and result stand the test of time, a pro reactivation function of the LAT locus will have strong support. Similar approaches in the mouse model could reveal such a pro-reactivation function of LAT as well. HSV is also well documented to establish latent infections that can be reactivated in a variety of non-neural tissues including denervated mouse footpads or footpads following long-term acyclovir treatment, various nonneural tissues from rabbit, mouse, rat, and guinea pig including cornea, conjunctiva, and hair follicles in humans and LAT expression has been detected in many of these ((Al-Saadi et al., 1988; Claoue et al., 1987; Easty et al., 1987; Nicholls et al., 1996; Scriba, 1977, 1981; Shimeld et al., 1986; Shimeld et al., 1982; Tullo et al., 1985) and see (Kennedy et al., 2011) for a relatively recent review). These extra-neural sites of latency are usually dismissed but may be biologically relevant, especially in recurrent ocular shedding and eye disease in the rabbit and humans. Whether the LAT locus plays a direct role in promoting reactivation from such sites deserves further study.

How does the virus go latent in the first place?

The ubiquity of HSV1 in the human population is the result of the efficient establishment of latent infections that subsequently reactivate throughout the host's lifetime and transmit to new hosts. A long-lived question is how the virus evolved to interact with sensory neurons to promote the efficient establishment of latency, which requires viral replication within the sensory ganglia but also a self-limiting mechanism to prevent neurovirulence and transmission into the CNS. The discovery of the LAT (Stevens et al., 1987) and mapping of its promoter (Dobson et al., 1989) provided a powerful tool to examine latent 
phase transcription in TG neurons by in situ hybridization for the LATs or by using LAT promoter/beta-galactosidase reporter mutants (Margolis et al., 1992; Sawtell and Thompson, 1992a; Simmons et al., 1992; Speck and Simmons, 1992).

A somewhat unexpected result common to all these studies was that the acute stage of infection in the TG (examined at 48 hours postinfection and later) was characterized by neurons expressing viral proteins and others expressing only the LATs or the LAT promoter. A few neurons were detected that expressed both, but these were rare. These data were interpreted to suggest that latent and lytic pathways in neurons were district from each other (Lachmann and Efstathiou, 1997; Margolis et al., 1992; Sawtell and Thompson, 1992b; Simmons et al., 1992; Speck and Simmons, 1992), and that the lytic and latent viral transcriptional programs in neurons were regulated in ways that were not understood. Hypotheses were proposed to explain this transcriptional programmatic duality including differential lytic/latent expression in neuronal subtypes, (Cabrera et al., 2018; Yang et al., 2000), transition from some acute gene expression into the latent program (Proenca et al., 2008), failure of VP16 to be transported to neuronal nuclei (Sears et al., 1991; Steiner et al., 1990), alternative regulation of gene expression (Kosz-Vnenchak et al., 1993), strict nonnuclear compartmentalization of essential co-activators such as HCF-1 specifically in neurons (Kristie et al., 1999), or that its interaction with alternate neuronally expressed cofactors like HCF-2, Oct-2 or Brn3 might inhibit its function (Liang et al., 2009; Lillycrop et al., 1993; Nogueira et al., 2004). Any or all of these mechanisms may act to constrain virus entry into the lytic phase in neurons, although replication in TG neurons is required to promote the efficient establishment of latency (Field et al., 1982; Field and Wildy, 1978; Katz et al., 1990; Kramer and Coen, 1995; Thompson and Sawtell, 2000), for review see (Hill, 1985; Roizman et al., 2013). To avoid injury or death of the host, this entry into the lytic cycle in neurons must be tightly controlled.

Several lines of investigation support the concept that VP16 and its unusual regulation in neurons plays a central role in the choice between latent and lytic 
infection (Sawtell and Thompson, 2016; Sawtell et al., 2011; Thompson et al., 2009). In the absence of the VP16 transactivation function latency is favored over acute viral replication in TG neurons in vivo (Sawtell and Thompson, 2016; Sawtell et al., 2011; Steiner et al., 1990; Thompson et al., 2009). During retrograde transport of HSV nucleocapsid/tegument through axons in cultured neurons loosely associated tegument proteins including VP16 are left behind and this presumably favors quiescent/latent infection in cultured neurons infected via axons (Aggarwal et al., 2012; Diefenbach et al., 2008; Hafezi et al., 2012; Koyuncu et al., 2017). Live-cell analysis by fluorescence time-lapse recording of capsid/tegument complexes transporting retrograde in axons of cultured sensory neurons has revealed that while the majority of VP16 is lost from capsids prior to transport to the neural soma, small amounts of the protein co-transport in this experimental setting that could promote a small amount of lytic neuronal infection (Antinone and Smith, 2010; Smith, 2012). This mechanism likely promotes latency in neurons (Hafezi et al., 2012; Koyuncu et al., 2017). Importantly, in all in vitro and in vivo models, significant viral replication occurs in cultured and sensory ganglion neurons demonstrating that these neurons can support lytic viral replication if the lytic cycle is initiated.

Replacing the VP16 gene promoter with that of another leaky late gene, VP5, resulted in normal viral replication on the mouse eye, but $>100$-fold reduced virus replication in TG (Thompson et al., 2009). Likewise, mutations in putative factor binding sites near and downstream of the VP16 TATA box also resulted in wild type replication on mouse eyes, and greatly reduced viral replication in TG (Sawtell and Thompson, 2016). In the latter study promoters of various kinetic classes (LAT, immediate early ICP0, and leaky late VP16) were employed to drive expression of $\mathrm{E}$. coli beta-galactosidase (B-gal) in otherwise wild type HSV1 strain 17syn+. Whole ganglion analysis of viral protein expression by immunohistochemistry and B-gal expression from the diverse promoters was employed to examine the earliest events that occur within TG neurons infected via axons from the cornea. The expected asynchrony of TG neuron infection was evident in the analysis of the time postinfection and the 


\section{Quantification of viral genome and infectious virus in TG at early times PI \\ Default Latent Transition \\ Program $\Longrightarrow$ into lytic}

20-32 hrs pi $\quad 32$ hrs pi onward

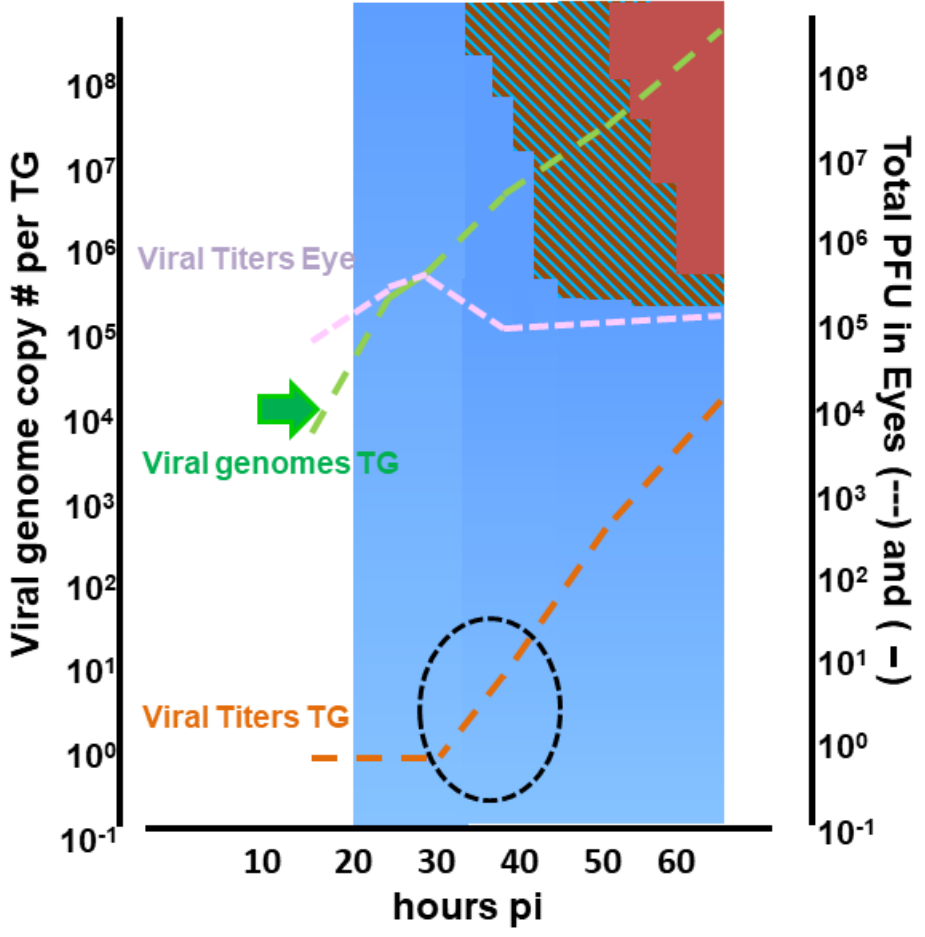

Figure 4. The colored field depicts the percent of positive neurons expressing the LAT promoter (Blue), only viral proteins (brown) or both (striped). Also shown are virus titers in the eye and TG and viral genomes in the TG (dashed lines).

number of neurons expressing viral proteins and promoter-driven B-gal prior to viral spread within the TG (up to 32 hours postinfection, Figure 4). At the earliest times examined (18 to $30 \mathrm{hpi}$ ), only LAT promoter-driven B-gal was detected in TG neurons.

Thus, the latent transcriptional program was engaged first in neurons infected via axons, consistent with the idea that VP16 did not arrive with the viral genome to initiate the lytic cascade. Of importance, B-gal activity and cognate 
viral protein expression in neurons was detected simultaneously in neurons (e.g. viral proteins including VP16 were detected in all neurons expressing Bgal from the VP16 promoter). The same was true of neurons marked by the ICPO promoter, indicating simultaneous expression of the native promoters and the transgenes.

Viral proteins were first detected about 14 hours after LAT promoter driven Bgal, and only in neurons previously marked by LAT promoter expression. Since the LAT promoter is strongly repressed by ICP4 in cells including neurons during acute productive infection (Batchelor and O'Hare, 1990; Farrell et al., 1994; Margolis et al., 1992; Sawtell and Thompson, 1992a), we concluded that the viral protein expression observed at these early times postinfection occurred in neurons transitioning out of the acute stage latent program into the lytic cycle.

Mutants expressing a second copy of wild type VP16, the VP16TF deficient mutant, or a third copy of ICPO driven by the LAT promoter were examined to determine whether the de novo expression of either ICP0 or VP16 was sufficient to push neurons out of the default latent transcription program into the lytic program. If so, viral protein expression and virus production in TG would be expected to occur about 14 hours earlier than that seen with wild type HSV1 infection. Early viral protein expression and infectious virus production was seen in TG of mice infected with the mutant expressing VP16 from the LAT promoter, but not in those infected with the LAT driven VP16TF mutant or ICP0 gene. Therefore, de novo expression of VP16, but not of ICP0, precipitated entry into lytic infection in TG neurons and the transactivation function of VP16 was required for this.

However, the requirement for the VP16 transactivation function is not absolute in so far as VP16TF viruses replicate to some extent in TG albeit at a 100 fold reduction (Sawtell et al., 2011; Tal-Singer et al., 1999; Thompson et al., 2009). High genome copy number could potentially override a requirement for VP16TF and this is supported by the finding that strategies increasing surface 
replication also increase replication in the TG (Sawtell et al., 2011; Thompson et al., 2009).

A specific region of the VP16 promoter regulated the transition into the lytic transcription program

The region of the VP16 promoter near and downstream of the VP16 TATA box is dispensable for normal leaky late kinetics (Lieu and Wagner, 2000). Thompson and Sawtell found that $3 \mathrm{bp}$ mutations in two putative factor binding sites in this region resulted in wild type virus replication in cultured cells and on the mouse eye, but nearly completely ablated the ability of the virus to transition out of the default latent pathway ( $2 \%$ transition vs. $30 \%$ at 44 hours postinfection (Sawtell and Thompson, 2016)). Recently a targeted replacement the HSV1 VP16 promoter sequences with those of HSV2 was generated and tested in mice. This demonstrated that the type 2 VP16 promoter also directs pre-immediate early VP16 expression and does so with greater efficiency during acute infection and following hyperthermic stress induced reactivation from latency (Thompson and Sawtell, 2019).

Combined, the studies offer strong support for the hypotheses that:

(i) VP16 is generally not transported retrograde in axons, favoring latency in neurons.

(ii) The VP16 promoter contains elements required for the de novo preimmediate early production of VP16, which drives exit from a default latent pathway into lytic viral replication in neurons.

(iii) Production of this VP16 is not the result of random "phase 1" type transcription seen in persistently infected cultures of primary neurons treated with AKT or protease inhibitors (Cliffe et al., 2015; Kim et al., 2012).

(iv) Latency is established by default in sensory neurons because VP16 does not arrive with the viral genome. Subsequent reactivation of HSV from the default, or consolidated latent state requires de novo VP16 production, and at least for exit from the default latent state this is mediated specifically by the VP16 promoter (Sawtell and Thompson, 2016; Thompson et al., 2009). 


\section{Events during the consolidation of HSV latency}

Assembly of chromatin structures on latent viral genomes is thought to be an important aspect of silencing the genome. In cultured cells viral DNA is rapidly associated with histones and chromatin is rapidly assembled, occurring in the first thirty minutes post infection (Roizman et al., 2005). This appears to be a multi-step and curiously slow process in TG neurons in vivo with initial events detectable at 7 days postinfection and modifications associated with silencing of genes such as heterochromatin formation occurring on lytic promoters after two weeks post infection, whereas the LAT promoter is associated with euchromatin at this time (for review see (Conn and Schang, 2013; Knipe, 2015; Kristie, 2015; Roizman et al., 2013)). Since viral gene expression ceases well before this time, this process may be more important for maintaining latency rather than the initial formation of latent infections. In support of this idea, recent studies suggest that chromatin insulator sequences and their binding proteins may maintain boundaries between regions of the latent HSV genome that are actively transcribed (e.g. the LAT locus) from the Iytic phase genes that are silenced (Lee et al., 2018; Washington et al., 2018b; Watson et al., 2018).

Part of the difficulty in understanding the effects of chromatin modifications and boundaries is that latent viral genomes are diverse in these properties. Approaches employed on whole tissues can only detect changes averaged over these millions of latent genomes. Lomonte and co-workers have developed methods to take such analyses to the next level in single neuronal nuclei. As expected, they detected multiple genomes in many neurons. What was not expected is that some of these are intimately associated with PML containing nuclear bodies, whereas others in the same nucleus are not. Also, of interest, some genomes express LAT locus RNAs, whereas others in the same nucleus do not. The silencing properties of these PML-NBs are thought to provide an intrinsic anti-viral defense mechanism that serves to promote latency (Cohen et al., 2018; Lomonte, 2016; Maroui et al., 2016). 
Efstathiou and colleagues developed a method to historically interrogate viral promoter expression in individual neurons that survive the acute stage of infection. Employing the Cre reporter mouse strain ROSA26R in combination with viral mutants that express Cre from various promoters they discovered that promoter expression in neurons that survive is far more frequent than previously thought (Proenca et al., 2008; Proenca et al., 2011; Proenca et al., 2015). However, the extent of production of the relevant viral proteins is not yet known. Another group employed this assay to examine the potential expression of viral promoters for genes encoding proteins that are important targets for immune surveillance. Evidence for the expression of these promoters suggest periodic expression of these promoters might be one mechanism whereby long-term immunity is maintained (Russell and Tscharke, 2016).

A role for HSV 1 latency/reactivation in the development of neurodegenerative disorders

The neurotropic nature of HSV and VZV, the extensive data identifying these viruses in the human CNS at autopsy or identification of virus in the cerebrospinal fluid together with the concept of viral latency and reactivation in the trigeminal ganglion led to the hypothesis "that reactivation of the same dormant viral material travelling centripetally instead might be the cause of the "degenerative" lesions typical both of $A D$ and of the normal aged brain." -MJ Ball (Ball, 1982). In 1997 Itzhaki et al. provided evidence that the combination of HSV1 in brain and carriage of an APOE-e4 allele is a strong risk factor for AD (Itzhaki et al., 1997; Lin et al., 1997). Evidence is now emerging that directly supports the concept that HSV1 infection is a major risk factor in the development of Alzheimer's Disease (reviewed in (Itzhaki, 2018; Lathe et al., 2019)). This concept has been met with much skepticism over the years for reasons including the high prevalence of $\mathrm{HSV}$ infection relative to $A D$ and the correlative nature of the studies. Clinical trials are now ongoing to test the efficacy of valacyclovir in individuals with mild AD (ClinicalTrials.gov Identifier: NCT03282916). Animal models are under development, and in human-ApoE4targeted replacement mouse, long-term HSV1 infected but not mock-infected 
mice exhibited spatial memory deficits and CNS pathology consistent with AD. HSV protein was detected in the hippocampus but was extremely rarely (work in progress). Such models will allow efficacy of antiviral treatments to be tested and investigation into the mechanisms of disease initiation and progression.

\section{Conclusions}

Increasingly sensitive methods to detect viral transcriptional activity from the latent viral genome have modified the notion of a strictly "silent" vs "active" genome (Collins-McMillen and Goodrum, 2017). However, the basic concepts of latency and reactivation based on detection of infectious virus remain solid fundamental concepts. From our vantage point, the field has three major challenges. The first is recognizing that all models have limitations. Recognizing the limitations and advantages of diverse models is necessary for integration of information from all models. Second, harnessing the advancing single-cell approaches for the investigation of HSV latency and reactivation in complex as well as simpler culture contexts. Third, recognizing that both complexity and reductionism have a role to play in future progress in understanding the intricacies of latency and reactivation in the nervous system. An excellent example of the combined power of these approaches was recently published (Cabrera et al., 2018). All models have advantages and limitations and the goal remains to relate what is learned to what is known about human/virus interactions, expanding our overall understanding of HSV pathogenesis.

Reactivation is highly restricted at the cellular level both in vivo and in vitro, consistent with the fact that maintaining latency is essential for the long-term survival of the virus in the host. Importantly, the mere presence of RNA related to viral lytic genes in the context of latency in vivo does not necessarily correlate with either viral protein expression (exit from latency) or reactivation (infectious virus). More startling is the revelation that even in homogenous cultures of neurons collectively stimulated by a potent inhibitor, reactivation occurs in only a small percentage of neurons. This feature of reactivation makes it extremely difficult to interpret analyses on the whole population. 
Distinguishing viral pro-reactivation from anti-reactivation transcriptional activity and how this activity is distributed on the viral genome as well as among the individual latently infected neurons is required before sufficient understanding of the significance of global transcriptional activation profiles can be interpreted.

We do not yet completely understand the significance of RNA transcription detected in latently infected ganglia, or under phase 1 conditions in cultured neurons. For example, Krause and colleagues demonstrated that viral transcription during latency that occurs in the absence of ICP27 protein results in splicing at sites that are normally suppressed, disrupting viral ORFs. Thus, they hypothesize HSV-1 may take advantage of host splicing machinery to restrict expression of randomly activated antigenic viral genes to achieve immune evasion (Tang et al., 2019). As we search for and query models in which viral reactivation is more robust, it is important to remember that the alpha herpesviruses evolved to remain latent most of the time and that productive reactivation from latency is a rare event at the cellular and viral genome level. Major remaining challenges include the characterization of the composition of the viral transcriptional activity within individual latently infected cells following a reactivation stimulus, the functional relevance of this activity in promoting or suppressing viral protein production, and whether this activity proceeds to reactivation. In the great majority of latently infected neurons the 100 s of thousands of latent genomes distributed in them remain latent. From this perspective, the methodologies are rapidly evolving that will support the analysis of transcriptomes at the single neuron level isolated from the relevant tissues (Cao et al., 2017; Hu et al., 2018; Rosenberg et al., 2018).

While the animal models of HSV latency/reactivation are not perfect, they have proven to support the complex viral life cycle with reasonable fidelity and these models approximate the level of complexity encountered in the human host. The simple act of axotomizing and explanting the ganglia results in changes that yield outcomes that do not align with the requirements for productive reactivation in the in vivo context such as the requirement of the VP16 
transactivation function to initiate detectable viral protein synthesis (compare (Steiner et al., 1990) to (Thompson et al., 2009). It is becoming increasingly apparent that properties of a complex system cannot be reduced to the components of a system because they depend on many interactions. Emergent properties of a complex system are lost when a system is stripped down to eliminate "extraneous" interactions or "complicating" interactions, with surrounding cells including satellite cells, resident glial and microglial cells, and infiltrating immune cells. In the pursuit of understanding HSV reactivation, a revival of reductionist approaches and models has arisen. The development of an in vitro latency model that provides a platform for dissecting host cell signaling pathways involved in viral genome entry into latency, its maintenance, and its activation would be an important tool. Ideally such a model could yield hypotheses testable in the more complex in vivo setting. However, defining the limitations to all models and approaches used to probe outcomes in these models is a critical component of the scientific process.

\section{References}

Abner, E., Stoszko, M., Zeng, L., Chen, H.C., Izquierdo-Bouldstridge, A., Konuma, T., Zorita, E., Fanunza, E., Zhang, Q., Mahmoudi, T., et al. (2018). A New Quinoline BRD4 Inhibitor Targets a Distinct Latent HIV-1 Reservoir for Reactivation from Other "Shock" Drugs. Journal of virology 92.

Ace, C.I., Dalrymple, M.A., Ramsay, F.H., Preston, V.G., and Preston, C.M. (1988). Mutational analysis of the herpes simplex virus type 1 trans-inducing factor Vmw65. The Journal of general virology 69, 2595-2605.

Ace, C.I., McKee, T.A., Ryan, J.M., Cameron, J.M., and Preston, C.M. (1989). Construction and characterization of a herpes simplex virus type 1 mutant unable to transinduce immediate-early gene expression. Journal of virology 63, 2260-2269.

Aggarwal, A., Miranda-Saksena, M., Boadle, R.A., Kelly, B.J., Diefenbach, R.J., Alam, W., and Cunningham, A.L. (2012). Ultrastructural Visualization of Individual Tegument Protein Dissociation during Entry of Herpes Simplex Virus 1 into Human and Rat Dorsal Root Ganglion Neurons. Journal of virology $86,6123-6137$. 
Agyemang, E., Magaret, A.S., Selke, S., Johnston, C., Corey, L., and Wald, A. (2018). Herpes Simplex Virus Shedding Rate: Surrogate Outcome for Genital Herpes Recurrence Frequency and Lesion Rates, and Phase 2 Clinical Trials End Point for Evaluating Efficacy of Antivirals. The Journal of infectious diseases.

Ahmed, R., and Stevens, J.G. (1990). Viral persistence. In B N Fields Virology, Raven Press, New York, NY.

Al-Saadi, S.A., Gross, P., and Wildy, P. (1988). Herpes simplex virus type 2 latency in the footpad of mice: effect of acycloguanosine on the recovery of virus. The Journal of general virology 69 ( Pt 2), 433-438.

Alfonso-Dunn, R., Turner, A.W., Jean Beltran, P.M., Arbuckle, J.H., Budayeva, H.G., Cristea, I.M., and Kristie, T.M. (2017). Transcriptional Elongation of HSV Immediate Early Genes by the Super Elongation Complex Drives Lytic Infection and Reactivation from Latency. Cell host and microbe 21, 507-517 e505.

Andrewes, C.H. (1957). Latent Virus Infections. Nature 180, 788.

Antinone, S.E., and Smith, G.A. (2010). Retrograde axon transport of herpes simplex virus and pseudorabies virus: a live-cell comparative analysis. Journal of virology 84, 1504-1512.

Azarkh, Y., Gilden, D., and Cohrs, R.J. (2010). Molecular characterization of varicella zoster virus in latently infected human ganglia: physical state and abundance of VZV DNA, Quantitation of viral transcripts and detection of VZV-specific proteins. Current topics in microbiology and immunology 342, 229-241.

Azwa, A., and Barton, S.E. (2009). Aspects of herpes simplex virus: a clinical review. J Fam Plann Reprod Health Care 35, 237-242.

Bain, J., McLauchlan, H., Elliott, M., and Cohen, P. (2003). The specificities of protein kinase inhibitors: an update. The Biochemical journal 371, 199-204.

Bain, J., Plater, L., Elliott, M., Shpiro, N., Hastie, C.J., McLauchlan, H., Klevernic, I., Arthur, J.S., Alessi, D.R., and Cohen, P. (2007). The selectivity of protein kinase inhibitors: a further update. The Biochemical journal 408, 297-315. 
Baird, N.L., Zhu, S., Pearce, C.M., and Viejo-Borbolla, A. (2019). Current In Vitro Models to Study Varicella Zoster Virus Latency and Reactivation. Viruses 11.

Balakrishnan, L., and Milavetz, B. (2017). Epigenetic Regulation of Viral Biological Processes. Viruses 9.

Ball, M.J. (1982). "Limbic predilection in Alzheimer dementia: is reactivated herpesvirus involved?". Can J Neurol Sci 9, 303-306.

Baringer, J.R., and Swoveland, P. (1973). Herpesvirus hominis: Isolation from Human Trigeminal Ganglion. New England Journal of Medicine 288, 648-650.

Bastian, F.O., Rabson, A.S., Yee, C.L., and Tralka, T.S. (1972). Herpesvirus hominis: Isolation from Human Trigeminal Ganglion. Science 178, 306-307.

Batchelor, A.H., and O'Hare, P. (1990). Regulation and cell-type-specific activity of a promoter located upstream of the latency-associated transcript of herpes simplex virus type 1 . Journal of virology $64,3269-3279$.

Batchelor, A.H., Wilcox, K.W., and O'Hare, P. (1994). Binding and repression of the latency-associated promoter of herpes simplex virus by the immediate early $175 \mathrm{~K}$ protein. The Journal of general virology $75,753-767$.

Behring, E.A., and Kitasato, S. (1890). Uber das Zustandekommen der Diphtherie-Immunität und der Tetanus, Immunität bei Thieren. Deutsch Med Wochenschrift 49, 1130-1145.

Bensussen, A., Torres-Sosa, C., Gonzalez, R.A., and Diaz, J. (2018). Dynamics of the Gene Regulatory Network of HIV-1 and the Role of Viral Non-coding RNAs on Latency Reversion. Frontiers in physiology 9, 1364.

Bertke, A.S., Patel, A., and Krause, P.R. (2007). Herpes simplex virus latencyassociated transcript sequence downstream of the promoter influences typespecific reactivation and viral neurotropism. Journal of virology 81 , 6605-6613.

Bloom, D.C. (2016). Alphaherpesvirus Latency: A Dynamic State of Transcription and Reactivation. Advances in virus research 94, 53-80.

Bloom, D.C., Hill, J.M., Devi-Rao, G., Wagner, E.K., Feldman, L.T., and Stevens, J.G. (1996). A 348-base-pair region in the latency-associated 
transcript facilitates herpes simplex virus type 1 reactivation. Journal of virology 70, 2449-2459.

Blyth, W.A., Harbour, D.A., and Hill, T.J. (1984). Pathogenesis of zosteriform spread of herpes simplex virus in the mouse. The Journal of general virology $65,1477-1486$.

Blyth, W.A., Hill, T.J., and Harbour, D.A. (1981). Mechanisms of control of latent herpes simplex virus infection in the skin, and eye, . in: Herpetic Eye Disease( Blyth, W A, Hill, T J, and Harbour, D A, ed), Springer-Verlag (Bergmann), 43-47.

Bolivar, F., Rodriguez, R.L., Betlach, M.C., and Boyer, H.W. (1977). Construction and characterization of new cloning vehicles. I. Ampicillinresistant derivatives of the plasmid pMB9. Gene analysis techniques 2, 75-93.

Bourne, N., Perry, C.L., Banasik, B.N., Miller, A.L., White, M., Pyles, R.B., Schafer, H., and Milligan, G.N. (2018). Increased frequency of virus shedding by herpes simplex virus type 2-infected guinea pigs in the absence of CD4+ T lymphocytes. Journal of virology.

Branco, F.J., and Fraser, N.W. (2005). Herpes simplex virus type 1 latencyassociated transcript expression protects trigeminal ganglion neurons from apoptosis. Journal of virology 79, 9019-9025.

Burnet, F.M., and Williams, S.W. (1939). Herpes Simplex: A point of view. Med J Aust 1, 637-642.

Cabrera, J.R., Charron, A.J., and Leib, D.A. (2018). Neuronal subtype determines HSV-1 Latency-Associated-Transcript (LAT) promoter activity during latency. Journal of virology.

Cai, W., Astor, T.L., Liptak, L.M., Cho, C., Coen, D.M., and Schaffer, P.A. (1993). The herpes simplex virus type 1 regulatory protein ICPO enhances virus replication during acute infection and reactivation from latency. Journal of virology $67,7501-7512$.

Cai, W., and Schaffer, P.A. (1992). Herpes simplex virus type 1 ICP0 regulates expression of immediate- early, early, and late genes in productively infected cells. Journal of virology 66, 2904-2915. 
Camarena, V., Kobayashi, M., Kim, J.Y., Roehm, P., Perez, R., Gardner, J., Wilson, A.C., Mohr, I., and Chao, M.V. (2010). Nature and duration of growth factor signaling through receptor tyrosine kinases regulates HSV-1 latency in neurons. Cell host and microbe 8, 320-330.

Campbell, M.E., Palfreyman, J.W., and Preston, C.M. (1984). Identification of herpes simplex virus DNA sequences which encode a trans-acting polypeptide responsible for stimulation of immediate early transcription. Journal of molecular biology 180, 1-19.

Cao, J., Packer, J.S., Ramani, V., Cusanovich, D.A., Huynh, C., Daza, R., Qiu, X., Lee, C., Furlan, S.N., Steemers, F.J., et al. (2017). Comprehensive single-cell transcriptional profiling of a multicellular organism. Science 357, 661-667.

Carton, C.A., and Kilbourne, E.D. (1952). Activation of latent herpes simplex by trigeminal sensory-root section. New Engl J Med 246, 172-176.

Chen, Y.A., and Aravin, A.A. (2015). Non-Coding RNAs in Transcriptional Regulation: The review for Current Molecular Biology Reports. Current molecular biology reports 1, 10-18.

Claoue, C.M., Blyth, W.A., Hill, T.J., and Easty, D.L. (1987). Does herpes simplex virus establish latency in the eye of the mouse? Eye 1 ( $P t 4)$, $525-528$.

Cliffe, A.R., Arbuckle, J.H., Vogel, J.L., Geden, M.J., Rothbart, S.B., Cusack, C.L., Strahl, B.D., Kristie, T.M., and Deshmukh, M. (2015). Neuronal Stress Pathway Mediating a Histone Methyl/Phospho Switch Is Required for Herpes Simplex Virus Reactivation. Cell host and microbe 18, 649-658.

Cohen, C., Corpet, A., Roubille, S., Maroui, M.A., Poccardi, N., Rousseau, A., Kleijwegt, C., Binda, O., Texier, P., Sawtell, N., et al. (2018). Promyelocytic leukemia (PML) nuclear bodies (NBs) induce latent/quiescent HSV-1 genomes chromatinization through a PML NB/Histone H3.3/H3.3 Chaperone Axis. PLoS pathogens 14, e1007313.

Cohrs, R.J., Badani, H., Baird, N.L., White, T.M., Sanford, B., and Gilden, D. (2017). Induction of varicella zoster virus DNA replication in dissociated human trigeminal ganglia. Journal of neurovirology 23, 152-157. 
Collins-McMillen, D., and Goodrum, F.D. (2017). The loss of binary: Pushing the herpesvirus latency paradigm. Current clinical microbiology reports 4 , 124-131.

Conn, K.L., and Schang, L.M. (2013). Chromatin dynamics during lytic infection with herpes simplex virus 1. Viruses 5, 1758-1786.

Cook, M.L., Bastone, V.B., and Stevens, F.G. (1974). Evidence that neurons harbor latent herpes simplex virus. Infect Immun 9, 946-951.

Cook, M.L., and Stevens, J.G. (1976). Latent herpetic infections following experimental viraemia. The Journal of general virology $31,75-80$.

Cushing, H. (1905). The surgical aspects of major neuralgia of the trigeminal nerve.a report of twenty cases of operation on the gasserian ganglion, with anatomic and physiologic notes on the consequences of its removal. Journal of the American Medical Association XLIV, 860-865.

D'Aiuto, L., Bloom, D.C., Naciri, J.N., Smith, A., Edwards, T.G., McClain, L., Callio, J.A., Jessup, M., Wood, J., Chowdari, K., et al. (2019). Modeling Herpes Simplex Virus 1 Infections in Human Central Nervous System Neuronal Cells Using Two- and Three-Dimensional Cultures Derived from Induced Pluripotent Stem Cells. Journal of virology 93.

Dargan, D.J., Patel, A.H., and Subak-Sharpe, J.H. (1995). PREPs: herpes simplex virus type 1-specific particles produced by infected cells when viral DNA replication is blocked. Journal of virology 69, 4924-4932.

Davido, D.J., and Leib, D.A. (1996). Role of cis-acting sequences of the ICPO promoter of herpes simplex virus type 1 in viral pathogenesis, latency and reactivation. The Journal of general virology $77,1853-1863$.

Dejosez, M., Levine, S.S., Frampton, G.M., Whyte, W.A., Stratton, S.A., Barton, M.C., Gunaratne, P.H., Young, R.A., and Zwaka, T.P. (2010). Ronin/ Hcf-1 binds to a hyperconserved enhancer element and regulates genes involved in the growth of embryonic stem cells. Genes and development 24, 1479-1484.

Depledge, D., Ouwendijk, W.J.D., Sadaoka, T., E. Braspenning, S., Mori, Y.M., Cohrs, R., Verjans, G., and Breuer, J. (2018a). A spliced latency-associated VZV transcript maps antisense to the viral transactivator gene 61 , Vol 9. 
Depledge, D.P., Sadaoka, T., and Ouwendijk, W.J.D. (2018b). Molecular Aspects of Varicella-Zoster Virus Latency. Viruses 10.

Dhanoa, J.K., Sethi, R.S., Verma, R., Arora, J.S., and Mukhopadhyay, C.S. (2018). Long non-coding RNA: its evolutionary relics and biological implications in mammals: a review. Journal of animal science and technology 60, 25.

Diefenbach, R.J., Miranda-Saksena, M., Douglas, M.W., and Cunningham, A.L. (2008). Transport and egress of herpes simplex virus in neurons. Reviews in medical virology 18, 35-51.

Dobson, A.T., Sederati, F., Devi-Rao, G., Flanagan, W.M., Farrell, M.J., Stevens, J.G., Wagner, E.K., and Feldman, L.T. (1989). Identification of the latency-associated transcript promoter by expression of rabbit beta-globin mRNA in mouse sensory nerve ganglia latently infected with a recombinant herpes simplex virus. Journal of virology $63,3844-3851$.

Doer, R. (1920). Etudes sur le virus de l'herpes febrile. Rev Gen Ophthalmol Paris 34, 409-421.

Doerig, C., Pizer, L.I., and Wilcox, C.L. (1991). Detection of the latencyassociated transcript in neuronal cultures during the latent infection with herpes simplex virus type 1. Virology 183, 423-426.

Doll, J.R., Hoebe, K., Thompson, R.L., and Sawtell, N.M. (2020). Resolution of herpes simplex virus reactivation in vivo results in neuronal destruction. PLoS pathogens 16, e1008296.

Doll, J.R., and Sawtell, N.M. (2017). Analysis of Herpes Simplex Virus Reactivation in Explant Reveals a Method-Dependent Difference in Measured Timing of Reactivation. Journal of virology 91.

Dulbecco, R., and Vogt, M. (1953). Some problems of animal virology as studied by the plaque technique. . Cold Spring Harbor Symp Quant Biol 18, 273-279.

Easty, D.L., Shimeld, C., Claoue, C.M., and Menage, M. (1987). Herpes simplex virus isolation in chronic stromal keratitis: human and laboratory studies. Current eye research 6, 69-74. 
Edwards, T.G., and Bloom, D.C. (2019). Lund Human Mesencephalic (LUHMES) Neuronal Cell Line Supports Herpes Simplex Virus 1 Latency In Vitro. Journal of virology 93.

Efstathiou, S., Minson, A.C., Field, H.J., Anderson, J.R., and Wildy, P. (1986). Detection of herpes simplex virus-specific DNA sequences in latently infected mice and in humans. Journal of virology $57,446-455$.

Everett, R.D. (2000). ICP0, a regulator of herpes simplex virus during lytic and latent infection. BioEssays : news and reviews in molecular, cellular and developmental biology 22, 761-770.

Fabian, M.A., Biggs, W.H., 3rd, Treiber, D.K., Atteridge, C.E., Azimioara, M.D., Benedetti, M.G., Carter, T.A., Ciceri, P., Edeen, P.T., Floyd, M., et al. (2005). A small molecule-kinase interaction map for clinical kinase inhibitors. Nature biotechnology 23, 329-336.

Farrell, M.J., Dobson, A.T., and Feldman, L.T. (1991). Herpes simplex virus latency-associated transcript is a stable intron. Proceedings of the National Academy of Sciences of the United States of America 88, 790-794.

Farrell, M.J., Margolis, T.P., Gomes, W.A., and Feldman, L.T. (1994). Effect of the transcription start region of the herpes simplex virus type 1 latencyassociated transcript promoter on expression of productively infected neurons in vivo. Journal of virology 68, 5337-5343.

Feldman, L.T., Ellison, A.R., Voytek, C.C., Yang, L., Krause, P., and Margolis, T.P. (2002). Spontaneous molecular reactivation of herpes simplex virus type 1 latency in mice. Proceedings of the National Academy of Sciences of the United States of America 99, 978-983.

Field, H.J., Anderson, J.R., and Wildy, P. (1982). Atypical patterns of neural infection produced in mice by drug- resistant strains of herpes simplex virus. The Journal of general virology 59, 91-99.

Field, H.J., Bell, S.E., Elion, G.B., Nash, A.A., and Wildy, P. (1979). Effect of acycloguanosine treatment of acute and latent herpes simplex infections in mice. Antimicrobial agents and chemotherapy 15, 554-561.

Field, H.J., and Wildy, P. (1978). The pathogenicity of thymidine kinasedeficient mutants of herpes simplex virus in mice. The Journal of hygiene 81 , 267-277. 
Finlay, G.M., and MacCallim, F.O. (1940). Lancet, 259-261.

Fraser, N.W., Block, T.M., and Spivack, J.G. (1992). The latency-associated transcripts of herpes simplex virus: RNA in search of function. Virology 191, 1-8.

Fraser, N.W., Lawrence, W.C., Wroblewska, Z., Gilden, D.H., and Koprowski, H. (1981). Herpes simplex type 1 DNA in human brain tissue. Proc Natl Acad Sci USA 78, 6461-6465.

Friedenwald, J.S. (1923). Studies in the virus of herpes simplex. Arch Ophthalmol 52, 105-131.

Fulop, T., Itzhaki, R.F., Balin, B.J., Miklossy, J., and Barron, A.E. (2018). Role of Microbes in the Development of Alzheimer's Disease: State of the Art - An International Symposium Presented at the 2017 IAGG Congress in San Francisco. Frontiers in genetics 9, 362.

Gall, J.G., and Pardue, M.L. (1969). Formation and detection of RNA-DNA hybrid molecules in cytological preparations. Proc Natl Acad Sci USA 63, 378-383.

Garber, D.A., Schaffer, P.A., and Knipe, D.M. (1997). A LAT-associated function reduces productive-cycle gene expression during acute infection of murine sensory neurons with herpes simplex virus type 1. Journal of virology 71, 5885-5893.

Gershon, A.A., Breuer, J., Cohen, J.I., Cohrs, R.J., Gershon, M.D., Gilden, D., Grose, C., Hambleton, S., Kennedy, P.G., Oxman, M.N., et al. (2015). Varicella zoster virus infection. Nature reviews Disease primers 1, 15016.

Giordani, N.V., Neumann, D.M., Kwiatkowski, D.L., Bhattacharjee, P.S., McAnany, P.K., Hill, J.M., and Bloom, D.C. (2008). During herpes simplex virus type 1 infection of rabbits, the ability to express the latency-associated transcript increases latent-phase transcription of lytic genes. Journal of virology 82, 6056-6060.

Glynn, J.R., Biraro, S., and Weiss, H.A. (2009). Herpes simplex virus type 2: a key role in HIV incidence. Aids 23, 1595-1598.

Good, R.A., and Campbell, B. (1948). The Precipitation of Latent Herpes simplex Encephalitis by Anaphylaetie Shock. . Proc Soc Expt Bio Med 68, 82-87. 
Goodpasture, E.W. (1925a). The axis cylinders of peripheral nerves as portals of entry to the central nervous system for the virus of herpes simplex in experimentally infected rabbits. . Amer J Path 1, 11-28.

Goodpasture, E.W. (1925b). The pathways of infection of the central nervous system in herpetic encephalitis of rabbits contracted by contact, with a comparative comment on medullary lesions in a case of human poliomyelitis. Amer J Path 1, 29-46.

Goodpasture, E.W. (1929). Herpetic infections with special reference to involvement of the nervous system. Medicine 8, 223-235.

Goodpasture, E.W., and Teague, O. (1923). Transmission of the virus of herpes fibrilis along nerves in experimentally infected rabbits. $\mathrm{J}$ med Res 44, 139-184.

Gottlieb, S.L., Giersing, B., Boily, M.C., Chesson, H., Looker, K.J., Schiffer, J., Spicknall, I., Hutubessy, R., Broutet, N., and Group, W.H.V.I.M.M.W. (2017). Modelling efforts needed to advance herpes simplex virus (HSV) vaccine development: Key findings from the World Health Organization Consultation on HSV Vaccine Impact Modelling. Vaccine.

Gruter, W. (1920). Experimental and clinical studies on herpes cornea. Klin Monatsbl Augenh 65, 398-399.

Hafezi, W., Lorentzen, E.U., Eing, B.R., Muller, M., King, N.J., Klupp, B., Mettenleiter, T.C., and Kuhn, J.E. (2012). Entry of herpes simplex virus type 1 (HSV-1) into the distal axons of trigeminal neurons favors the onset of nonproductive, silent infection. PLoS pathogens 8, e1002679.

Halford, W.P., Kemp, C.D., Isler, J.A., Davido, D.J., and Schaffer, P.A. (2001). ICP0, ICP4, or VP16 expressed from adenovirus vectors induces reactivation of latent herpes simplex virus type 1 in primary cultures of latently infected trigeminal ganglion cells. Journal of virology 75, 6143-6153.

Halford, W.P., and Schaffer, P.A. (2001). ICPO is required for efficient reactivation of herpes simplex virus type 1 from neuronal latency. Journal of virology 75, 3240-3249.

Harbour, D.A., Blyth, W.A., and Hill, T.J. (1978). Prostaglandins enhance spread of herpes simplex virus in cell cultures. . J Gen Virol 41, 87-95. 
Harbour, D.A., Hill, T.J., and Blyth, W.A. (1983). Recurrent herpes simplex in the mouse: inflammation in the skin and activation of virus in the ganglia following peripheral stimulation. The Journal of general virology 64 (Pt 7), 1491-1498.

Harbour, D.A., Hill, T.J., and Blyth, W.A., 1977, (1977). The effect of ultraviolet light on primary herpes virus infection in the mouse,. Arch Virol 54, 367-372.

Harris, R.A., and Preston, C.M. (1991). Establishment of latency in vitro by the herpes simplex virus type 1 mutant in1814. The Journal of general virology 72, 907-913.

He, J.H., Han, Z.P., and Li, Y.G. (2014). Association between long non-coding RNA and human rare diseases (Review). Biomedical reports 2, 19-23.

Head, H., and Campbell, A.W. (1900). The pathology of herpes zoster and its bearing on sensory localization. Brain 23, 353-523.

Head, H., Campbell, A.W., and Kennedy, P.G.E. (1997). The pathology of Herpes Zoster and its bearing on sensory localisation. Reviews in Medical Virology 7, 131-143.

Held, K., and Derfuss, T. (2011). Control of HSV-1 latency in human trigeminal ganglia--current overview. Journal of neurovirology $17,518-527$.

Henderson, G., Perng, G.C., Nesburn, A.B., Wechsler, S.L., and Jones, C. (2004). The latency-related gene encoded by bovine herpesvirus 1 can suppress caspase 3 and caspase 9 cleavage during productive infection. Journal of neurovirology 10, 64-70.

Hill, J.M., Sedarati, F., Javier, R.T., Wagner, E.K., and Stevens, J.G. (1990). Herpes simplex virus latent phase transcription facilitates in vivo reactivation. Virology 174, 117-125.

Hill, T. (1985). The herpesviruses Vol 3, Vol 3 (Plenum Press, New York ).

Hill, T.J., Field, H.J., and Blyth, W.A. (1975). Acute and recurrent infection with herpes simplex virus in the mouse: a model for studying latency and recurrent disease. The Journal of general virology 28, 341-353.

Holden, M. (1932). The Nature and Properties of the Virus of Herpes. The Journal of infectious diseases 50, 218-236.

Hope-Simpson, R.E. (1965). The nature of herpes zoster: a long-term study and a new hypothesis. Proc R Soc Med 58, 9-20. 
Howard, P.W., Howard, T.L., and Johnson, D.C. (2013). Herpes simplex virus membrane proteins $\mathrm{gE} / \mathrm{gl}$ and US9 act cooperatively to promote transport of capsids and glycoproteins from neuron cell bodies into initial axon segments. Journal of virology $87,403-414$.

Howard, W.T. (1903). The pathology of labial and nasal herpes and of herpes of the body occurring in acute croupous pneumonia and their relation to socalled herpes zoster. . Amer J med Sci 125, 256-272.

Hoyt, C.S., and Billson, F.A. (1976). , Herpes simplex infection after blowout fractures. Lancet 2, 1364-1365.

Hu, P., Liu, J., Zhao, J., Wilkins, B.J., Lupino, K., Wu, H., and Pei, L. (2018). Single-nucleus transcriptomic survey of cell diversity and functional maturation in postnatal mammalian hearts. Genes and development 32, 1344-1357.

Hunsperger, E.A., and Wilcox, C.L. (2003). Caspase-3-dependent reactivation of latent herpes simplex virus type 1 in sensory neuronal cultures. Journal of neurovirology 9, 390-398.

Hurd, J., and Robinson, T.W.E. (1977). Herpes simplex: Aspects of reactivation in a mouse model. J Antimicrob Chemother 3, 99-106.

Indo, Y. (2018). NGF-dependent neurons and neurobiology of emotions and feelings: Lessons from congenital insensitivity to pain with anhidrosis. Neuroscience and biobehavioral reviews 87, 1-16.

Itzhaki, R.F. (2018). Corroboration of a Major Role for Herpes Simplex Virus Type 1 in Alzheimer's Disease. Frontiers in aging neuroscience 10, 324.

Itzhaki, R.F., Lin, W.R., Shang, D., Wilcock, G.K., Faragher, B., and Jamieson, G.A. (1997). Herpes simplex virus type 1 in brain and risk of Alzheimer's disease. Lancet 349, 241-244.

Itzhaki, R.F., and Wozniak, M.A. (2008). Herpes simplex virus type 1 in Alzheimer's disease: the enemy within. Journal of Alzheimer's disease : JAD 13, 393-405.

Izumi, K.M., and Stevens, J.G. (1990). Molecular and biological characterization of a herpes simplex virus type 1 (HSV-1) neuroinvasiveness gene. The Journal of experimental medicine 172, 487-496. 
Jacobson, J.G., Leib, D.A., Goldstein, D.J., Bogard, C.L., Schaffer, P.A., Weller, S.K., and Coen, D.M. (1989). A herpes simplex virus ribonucleotide reductase deletion mutant is defective for productive acute and reactivatable latent infections of mice and for replication in mouse cells. Virology 173, 276-283.

Jiang, X., Brown, D., Osorio, N., Hsiang, C., BenMohamed, L., and Wechsler, S.L. (2016). Increased neurovirulence and reactivation of the herpes simplex virus type 1 latency-associated transcript (LAT)-negative mutant dLAT2903 with a disrupted LAT miR-H2. Journal of neurovirology 22, 38-49.

Jiang, X., Brown, D., Osorio, N., Hsiang, C., Li, L., Chan, L., BenMohamed, L., and Wechsler, S.L. (2015). A herpes simplex virus type 1 mutant disrupted for microRNA H2 with increased neurovirulence and rate of reactivation. Journal of neurovirology 21, 199-209.

Jin, L., Peng, W., Perng, G.C., Brick, D.J., Nesburn, A.B., Jones, C., and Wechsler, S.L. (2003). Identification of herpes simplex virus type 1 latencyassociated transcript sequences that both inhibit apoptosis and enhance the spontaneous reactivation phenotype. Journal of virology 77, 6556-6561.

Jin, L., Perng, G.C., Mott, K.R., Osorio, N., Naito, J., Brick, D.J., Carpenter, D., Jones, C., and Wechsler, S.L. (2005). A herpes simplex virus type 1 mutant expressing a baculovirus inhibitor of apoptosis gene in place of latencyassociated transcript has a wild-type reactivation phenotype in the mouse. Journal of virology $79,12286-12295$.

Johnson, D.C., McDermott, M.R., Chrisp, C., and Glorioso, J.C. (1986). Pathogenicity in mice of herpes simplex virus type 2 mutants unable to express glycoprotein C. Journal of virology 58, 36-42.

Kato, A., Ando, T., Oda, S., Watanabe, M., Koyanagi, N., Arii, J., and Kawaguchi, Y. (2016). Roles of Us8A and Its Phosphorylation Mediated by Us3 in Herpes Simplex Virus 1 Pathogenesis. Journal of virology 90 , 5622-5635.

Katz, J.P., Bodin, E.T., and Coen, D.M. (1990). Quantitative polymerase chain reaction analysis of herpes simplex virus DNA in ganglia of mice infected with replication-incompetent mutants. Journal of virology 64, 4288-4295. 
Kawamura, Y., Bosch-Marce, M., Tang, S., Patel, A., and Krause, P.R. (2018). Herpes Simplex Virus 2 Latency-Associated Transcript (LAT) Region Mutations Do Not Identify a Role for LAT-Associated MicroRNAs in Viral Reactivation in Guinea Pig Genital Models. Journal of virology 92.

Kennedy, D.P., Clement, C., Arceneaux, R.L., Bhattacharjee, P.S., Huq, T.S., and Hill, J.M. (2011). Ocular herpes simplex virus type 1: is the cornea a reservoir for viral latency or a fast pit stop? Cornea 30, 251-259.

Khoury, G., Mota, T.M., Li, S., Tumpach, C., Lee, M.Y., Jacobson, J., Harty, L., Anderson, J.L., Lewin, S.R., and Purcell, D.F.J. (2018). HIV latency reversing agents act through Tat post translational modifications. Retrovirology 15, 36.

Kim, J.Y., Mandarino, A., Chao, M.V., Mohr, I., and Wilson, A.C. (2012). Transient reversal of episome silencing precedes VP16-dependent transcription during reactivation of latent HSV-1 in neurons. PLoS pathogens 8, e1002540.

Knickelbein, J.E., Khanna, K.M., Yee, M.B., Baty, C.J., Kinchington, P.R., and Hendricks, R.L. (2008). Noncytotoxic lytic granule-mediated CD8+ T cell inhibition of HSV-1 reactivation from neuronal latency. Science 322, 268-271.

Knipe, D. (2007). Fields Virology, Vol 2, 5 edn (Philadelphia: Lippincott Williams and Wilkins).

Knipe, D.M. (2015). Nuclear sensing of viral DNA, epigenetic regulation of herpes simplex virus infection, and innate immunity. Virology 479-480, 153-159.

Kobayashi, M., Kim, J.Y., Camarena, V., Roehm, P.C., Chao, M.V., Wilson, A.C., and Mohr, I. (2012). A primary neuron culture system for the study of herpes simplex virus latency and reactivation. Journal of visualized experiments : JoVE

Koch, R. (1890). Report of address at 10th International Medical Congress, Berlin, August 4, 1890. Deut Med Wochenschr 16, 756-757.

Kosz-Vnenchak, M., Jacobson, J., Coen, D.M., and Knipe, D.M. (1993). Evidence for a novel regulatory pathway for herpes simplex virus gene expression in trigeminal ganglion neurons. Journal of virology 67 , 5383-5393. 
Koyuncu, O.O., MacGibeny, M.A., Hogue, I.B., and Enquist, L.W. (2017). Compartmented neuronal cultures reveal two distinct mechanisms for alpha herpesvirus escape from genome silencing. PLoS pathogens 13, e1006608. Kramer, M.F., and Coen, D.M. (1995). Quantification of transcripts from the ICP4 and thymidine kinase genes in mouse ganglia latently infected with herpes simplex virus. Journal of virology 69, 1389-1399.

Kraupa, E. (1920). Zu Grüters ätiologischen Untersuchungen über den fieberhaften Herpes. Munch Med Wochenschr 67.

Krause, P.R., Stanberry, L.R., Bourne, N., Connelly, B., Kurawadwala, J.F., Patel, A., and Straus, S.E. (1995). Expression of the herpes simplex virus type 2 latency-associated transcript enhances spontaneous reactivation of genital herpes in latently infected guinea pigs. The Journal of experimental medicine 181, 297-306.

Kristie, T.M. (2015). Dynamic modulation of HSV chromatin drives initiation of infection and provides targets for epigenetic therapies. Virology 479-480, 555-561.

Kristie, T.M., Liang, Y., and Vogel, J.L. (2010). Control of alpha-herpesvirus IE gene expression by HCF-1 coupled chromatin modification activities. Biochimica et biophysica acta 1799, 257-265.

Kristie, T.M., and Roizman, B. (1987). Host cell proteins bind to the cis-acting site required for virion-mediated induction of herpes simplex virus 1 alpha genes. Proceedings of the National Academy of Sciences of the United States of America 84, 71-75.

Kristie, T.M., Vogel, J.L., and Sears, A.E. (1999). Nuclear localization of the C1 factor (host cell factor) in sensory neurons correlates with reactivation of herpes simplex virus from latency. Proceedings of the National Academy of Sciences of the United States of America 96, 1229-1233.

Kundratitz, K. (1925). U" ber die A" tiologie des Zoster and u"ber seine Beziehungen zu Varizellen. Wien Klin Wochenschr 38, 502-503.

Kurapati, S., Sadaoka, T., Rajbhandari, L., Jagdish, B., Shukla, P., Ali, M.A., Kim, Y.J., Lee, G., Cohen, J.I., and Venkatesan, A. (2017). Role of the JNK Pathway in Varicella-Zoster Virus Lytic Infection and Reactivation. Journal of virology 91 . 
Lachmann, R.H., and Efstathiou, S. (1997). Utilization of the herpes simplex virus type 1 latency-associated regulatory region to drive stable reporter gene expression in the nervous system. Journal of virology $71,3197-3207$.

Laemmle, L., Goldstein, R.S., and Kinchington, P.R. (2019). Modeling Varicella Zoster Virus Persistence and Reactivation - Closer to Resolving a Perplexing Persistent State. Frontiers in microbiology 10, 1634.

LaGuardia, J.J., Cohrs, R.J., and Gilden, D.H. (1999). Prevalence of varicellazoster virus DNA in dissociated human trigeminal ganglion neurons and nonneuronal cells. Journal of virology 73, 8571-8577.

Lahmidi, S., Yousefi, M., Dridi, S., Duplay, P., and Pearson, A. (2017). Dok-1 and Dok-2 Are Required To Maintain Herpes Simplex Virus 1-Specific CD8(+) T Cells in a Murine Model of Ocular Infection. Journal of virology 91.

Lam, Q., Smibert, C.A., Koop, K.E., Lavery, C., Capone, J.P., Weinheimer, S.P., and Smiley, J.R. (1996). Herpes simplex virus VP16 rescues viral mRNA from destruction by the virion host shutoff function. The EMBO journal 15, 2575-2581.

Lathe, R., Tzeng, N.S., and Itzhaki, R. (2019). Herpes Infections and Dementia: Rebutting Alternative Fact. Neurotherapeutics : the journal of the American Society for Experimental NeuroTherapeutics 16, 176-179.

Lee, J.S., Raja, P., Pan, D., Pesola, J.M., Coen, D.M., and Knipe, D.M. (2018). CCCTC-Binding Factor Acts as a Heterochromatin Barrier on Herpes Simplex Viral Latent Chromatin and Contributes to Poised Latent Infection. mBio 9.

Lee, S., Ives, A.M., and Bertke, A.S. (2015). Herpes Simplex Virus 1 Reactivates from Autonomic Ciliary Ganglia Independently from Sensory Trigeminal Ganglia To Cause Recurrent Ocular Disease. Journal of virology 89, 8383-8391.

Leib, D.A., Bogard, C.L., Kosz-Vnenchak, M., Hicks, K.A., Coen, D.M., Knipe, D.M., and Schaffer, P.A. (1989a). A deletion mutant of the latency-associated transcript of herpes simplex virus type 1 reactivates from the latent state with reduced frequency. Journal of virology 63, 2893-2900.

Leib, D.A., Coen, D.M., Bogard, C.L., Hicks, K.A., Yager, D.R., Knipe, D.M., Tyler, K.L., and Schaffer, P.A. (1989b). Immediate-early regulatory gene 
mutants define different stages in the establishment and reactivation of herpes simplex virus latency. Journal of virology 63, 759-768.

Levin, M.J., Cai, G.Y., Manchak, M.D., and Pizer, L.I. (2003). Varicella-zoster virus DNA in cells isolated from human trigeminal ganglia. Journal of virology 77, 6979-6987.

Liang, Y., Vogel, J.L., Narayanan, A., Peng, H., and Kristie, T.M. (2009). Inhibition of the histone demethylase LSD1 blocks alpha-herpesvirus lytic replication and reactivation from latency. Nature medicine 15, 1312-1317.

Lieberman, P.M. (2016). Epigenetics and Genetics of Viral Latency. Cell host and microbe 19, 619-628.

Lieu, P.T., and Wagner, E.K. (2000). Two leaky-late HSV-1 promoters differ significantly in structural architecture. Virology 272, 191-203.

Lillycrop, K.A., Estridge, J.K., and Latchman, D.S. (1993). The octamer binding protein Oct-2 inhibits transactivation of the herpes simplex virus immediateearly genes by the virion protein Vmw65. Virology 196, 888-891.

Lin, W.R., Casas, I., Wilcock, G.K., and Itzhaki, R.F. (1997). Neurotropic viruses and Alzheimer's disease: a search for varicella zoster virus DNA by the polymerase chain reaction. Journal of neurology, neurosurgery, and psychiatry $62,586-589$.

Liu, T., Khanna, K.M., Chen, X., Fink, D.J., and Hendricks, R.L. (2000). CD8(+) $\mathrm{T}$ cells can block herpes simplex virus type 1 (HSV-1) reactivation from latency in sensory neurons. The Journal of experimental medicine 191, 1459-1466.

Loewenstein, A. (1919). Experimental transmission of HSV-1 from human lesions to rabbit corneas. Munch Med Wochenschr 66, 769-770.

Loewenstein, A. (1920). Etiology of febrile herpes. Munch med Wochenschr 67, 1236-1237.

Lofgren, K.W., Stevens, J.G., Marsden, H.S., and Subak-Sharpe, J.H. (1977). Temperature-sensitive mutants of herpes simplex virus differ in the capacity to establish latent infections in mice. Virology $76,440-443$.

Lomonte, P. (2016). The interaction between herpes simplex virus 1 genome and promyelocytic leukemia nuclear bodies (PML-NBs) as a hallmark of the entry in latency. Microb Cell 3, 569-572. 
Looker, K.J., Magaret, A.S., May, M.T., Turner, K.M.E., Vickerman, P., Newman, L.M., and Gottlieb, S.L. (2017). First estimates of the global and regional incidence of neonatal herpes infection. The Lancet Global health 5 , e300-e309.

Mackem, S., and Roizman, B. (1982). Structural features of the herpes simplex virus alpha gene 4,0 , and 27 promoter-regulatory sequences which confer alpha regulation on chimeric thymidine kinase genes. Journal of virology 44, 939-949.

Mahalingam, R., Gershon, A., Gershon, M., Cohen, J.I., Arvin, A., Zerboni, L., Zhu, H., Gray, W., Messaoudi, I., and Traina-Dorge, V. (2019). Current In Vivo Models of Varicella-Zoster Virus Neurotropism. Viruses 11.

Margolis, T.P., Elfman, F.L., Leib, D., Pakpour, N., Apakupakul, K., Imai, Y., and Voytek, C. (2007). Spontaneous reactivation of herpes simplex virus type 1 in latently infected murine sensory ganglia. Journal of virology 81 , 11069-11074.

Margolis, T.P., Sedarati, F., Dobson, A.T., Feldman, L.T., and Stevens, J.G. (1992). Pathways of viral gene expression during acute neuronal infection with HSV-1. Virology 189, 150-160.

Markus, A., Lebenthal-Loinger, I., Yang, I.H., Kinchington, P.R., and Goldstein, R.S. (2015). An in vitro model of latency and reactivation of varicella zoster virus in human stem cell-derived neurons. PLoS pathogens 11, e1004885.

Maroui, M.A., Calle, A., Cohen, C., Streichenberger, N., Texier, P., Takissian, J., Rousseau, A., Poccardi, N., Welsch, J., Corpet, A., et al. (2016). Latency Entry of Herpes Simplex Virus 1 Is Determined by the Interaction of Its Genome with the Nuclear Environment. PLoS pathogens 12, e1005834.

McFarlane, M., Daksis, J.I., and Preston, C.M. (1992). Hexamethylene bisacetamide stimulates herpes simplex virus immediate early gene expression in the absence of trans-induction by Vmw65. The Journal of general virology 73, 285-292.

McKinney, C.C., Kim, M.J., Chen, D., and McBride, A.A. (2016). Brd4 Activates Early Viral Transcription upon Human Papillomavirus 18 Infection of Primary Keratinocytes. mBio 7. 
McLennan, J.L., and Darby, G. (1980). Herpes simplex virus latency: the cellular location of virus in dorsal root ganglia and the fate of the infected cell following virus activation. The Journal of general virology 51, 233-243.

Meignier, B., Longnecker, R., and Roizman, B. (1988). In vivo behavior of genetically engineered herpes simplex viruses R7017 and R7020: construction and evaluation in rodents. The Journal of infectious diseases $158,602-614$

Michaud, J., Praz, V., James Faresse, N., Jnbaptiste, C.K., Tyagi, S., Schutz, F., and Herr, W. (2013). HCFC1 is a common component of active human CpG-island promoters and coincides with ZNF143, THAP11, YY1, and GABP transcription factor occupancy. Genome research 23, 907-916.

Minocha, S., Sung, T.L., Villeneuve, D., Lammers, F., and Herr, W. (2016). Compensatory embryonic response to allele-specific inactivation of the murine X-linked gene Hcfc1. Developmental biology 412, 1-17.

Moffat, J.F., Stein, M.D., Kaneshima, H., and Arvin, A.M. (1995). Tropism of varicella-zoster virus for human CD4+ and CD8+ $\mathrm{T}$ lymphocytes and epidermal cells in SCID-hu mice. Journal of virology 69, 5236-5242.

Mukamal, K.J., Kronmal, R.A., Tracy, R.P., Cushman, M., and Siscovick, D.S. (2004). Traditional and novel risk factors in older adults: cardiovascular risk assessment late in life. Am J Geriatr Cardiol 13, 69-80.

Mukerjee, R., Kang, W., Suri, V., and Fraser, N.W. (2004). A non-consensus branch point plays an important role in determining the stability of the 2-kb LAT intron during acute and latent infections of herpes simplex virus type-1. Virology 324, 340-349.

Narayanan, A., Nogueira, M.L., Ruyechan, W.T., and Kristie, T.M. (2005). Combinatorial transcription of herpes simplex virus and varicella zoster virus immediate early genes is strictly determined by the cellular coactivator HCF-1. The Journal of biological chemistry 280, 1369-1375.

Negatsch, A., Mettenleiter, T.C., and Fuchs, W. (2011). Herpes simplex virus type 1 strain KOS carries a defective US9 and a mutated US8A gene. The Journal of general virology 92, 167-172. 
Nicholls, S.M., and Blyth, W.A. (1989). Quantification of herpes simplex virus infection in cervical ganglia of mice. The Journal of general virology 70 , 1779-1788.

Nicholls, S.M., Shimeld, C., Easty, D.L., and Hill, T.J. (1996). Recurrent herpes simplex after corneal transplantation in rats. Investigative ophthalmology and visual science $37,425-435$.

Nogueira, M.L., Wang, V.E., Tantin, D., Sharp, P.A., and Kristie, T.M. (2004). Herpes simplex virus infections are arrested in Oct-1-deficient cells. Proceedings of the National Academy of Sciences of the United States of America 101, 1473-1478.

O'Hare, P. (1993). The virion transactivator of herpes simplex virus. Seminars in Virology 4, 145-155.

O'Neill, F.J., Goldberg, R.J., and Rapp, F. (1972). Herpes simplex virus latency in cultured human cells following treatment with cytosine arabinoside. The Journal of general virology 14, 189-197.

Ouwendijk, W.J., and Verjans, G.M. (2015). Pathogenesis of varicelloviruses in primates. The Journal of pathology 235, 298-311.

Peng, W., Henderson, G., Perng, G.C., Nesburn, A.B., Wechsler, S.L., and Jones, C. (2003). The gene that encodes the herpes simplex virus type 1 latency-associated transcript influences the accumulation of transcripts (Bcl$\mathrm{x}(\mathrm{L})$ and $\mathrm{Bcl}-\mathrm{x}(\mathrm{S}))$ that encode apoptotic regulatory proteins. Journal of virology 77, 10714-10718.

Pepose, J.S., Keadle, T.L., and Morrison, L.A. (2006). Ocular herpes simplex: changing epidemiology, emerging disease patterns, and the potential of vaccine prevention and therapy. American journal of ophthalmology 141, 547-557.

Perdrau, J.R. (1925). The virus of herpes: Its immune reactions and its relation to that of encephalitis lethargica. Brit J Exper Path 6, 41-52.

Perdrau, J.R. (1931). Inactivation and Reactivation of the Virus of Herpes. Proceedings of the Royal Society of London 109, 304-308.

Perdrau, J.R. (1938). Persistence of the virus of herpes in rabbits immunised with living virus. The Journal of pathology and bacteriology 47, 447-455. 
Perng, G.C., Jones, C., Ciacci-Zanella, J., Stone, M., Henderson, G., Yukht, A., Slanina, S.M., Hofman, F.M., Ghiasi, H., Nesburn, A.B., et al. (2000a). Virus-induced neuronal apoptosis blocked by the herpes simplex virus latency-associated transcript. Science 287, 1500-1503.

Perng, G.C., Maguen, B., Jin, L., Mott, K.R., Osorio, N., Slanina, S.M., Yukht, A., Ghiasi, H., Nesburn, A.B., Inman, M., et al. (2002). A gene capable of blocking apoptosis can substitute for the herpes simplex virus type 1 latencyassociated transcript gene and restore wild-type reactivation levels. Journal of virology $76,1224-1235$.

Perng, G.C., Slanina, S.M., Yukht, A., Ghiasi, H., Nesburn, A.B., and Wechsler, S.L. (2000b). The latency-associated transcript gene enhances establishment of herpes simplex virus type 1 latency in rabbits. Journal of virology 74, 1885-1891.

Pesola, J.M., Zhu, J., Knipe, D.M., and Coen, D.M. (2005). Herpes simplex virus 1 immediate-early and early gene expression during reactivation from latency under conditions that prevent infectious virus production. Journal of virology 79, 14516-14525.

Phelan, D., Barrozo, E.R., and Bloom, D.C. (2017). HSV1 latent transcription and non-coding RNA: A critical retrospective. Journal of neuroimmunology 308, 65-101.

Pieknik, J.R., Bertke, A.S., and Krause, P.R. (2019). Herpes Simplex Virus 2 in Autonomic Ganglia: Evidence for Spontaneous Reactivation. Journal of virology 93.

Pieknik, J.R., Bertke, A.S., Tang, S., and Krause, P.R. (2018). A VP26mNeonGreen Capsid Fusion HSV-2 Mutant Reactivates from Viral Latency in the Guinea Pig Genital Model with Normal Kinetics. Viruses 10.

Plummer, G. (1964). Serological Comparison of the herpes simple viruses. $\mathrm{Br}$ J Exp Pathol 45, 135-141.

Plummer, G. (1973). Isolation of herpesviruses from the trigeminal ganglia of man, monkeys and cats. J Infect Dis 128, 345-348.

Plummer, G., Cleveland, P.H., and Stevens, C. (1967). Herpes simplex virus and paralysis of rabbits. Activation of the paralysis by adrenalin. British journal of experimental pathology 48, 390-394. 
Plummer, G., Goodheart, C.R., Miyagi, M., Skinner, G.R., Thouless, M.E., and Wildy, P. (1974). Herpes simplex viruses: discrimination of types and correlation between different characteristics. Virology 60, 206-216.

Plummer, G., Hollingsworth, D.C., Phuangsab, A., and Bowling, C.P. (1970). Chronic infections by herpes simplex viruses and by the horse and cat herpesviruses. Infect Immun 1, 351-355.

Plummer, G., Waner, J.L., and Bowling, C.P. (1968). Comparative studies of type 1 and type 2 and 'herpes simplex' viruses. British journal of experimental pathology 49, 202-208.

Pourchet, A., Modrek, A.S., Placantonakis, D.G., Mohr, I., and Wilson, A.C. (2017). Modeling HSV-1 Latency in Human Embryonic Stem Cell-Derived Neurons. Pathogens 6.

Preston, C.M., and McFarlane, M. (1998). Cytodifferentiating agents affect the replication of herpes simplex virus type 1 in the absence of functional VP16. Virology 249, 418-426.

Proenca, J.T., Coleman, H.M., Connor, V., Winton, D.J., and Efstathiou, S. (2008). A historical analysis of herpes simplex virus promoter activation in vivo reveals distinct populations of latently infected neurones. The Journal of general virology $89,2965-2974$.

Proenca, J.T., Coleman, H.M., Nicoll, M.P., Connor, V., Preston, C.M., Arthur, J., and Efstathiou, S. (2011). An investigation of HSV promoter activity compatible with latency establishment reveals VP16 independent activation of HSV immediate early promoters in sensory neurones. The Journal of general virology.

Proenca, J.T., Nelson, D., Nicoll, M.P., Connor, V., and Efstathiou, S. (2015). Analyses of HSV-1 latency and reactivation at the single cell level using fluorescent reporter mice. The Journal of general virology.

Pyles, R.B., Sawtell, N.M., and Thompson, R.L. (1992). Herpes simplex virus type 1 dUTPase mutants are attenuated for neurovirulence, neuroinvasiveness, and reactivation from latency. Journal of virology 66, 6706-6713.

Pyles, R.B., and Thompson, R.L. (1994a). Evidence that the herpes simplex virus type 1 uracil DNA glycosylase is required for efficient viral replication 
and latency in the murine nervous system. Journal of virology 68 , 4963-4972.

Pyles, R.B., and Thompson, R.L. (1994b). Mutations in accessory DNA replicating functions alter the relative mutation frequency of herpes simplex virus type 1 strains in cultured murine cells. Journal of virology 68 , 4514-4524.

Ramchandani, M., Selke, S., Magaret, A., Barnum, G., Huang, M.W., Corey, L., and Wald, A. (2017). Prospective cohort study showing persistent HSV-2 shedding in women with genital herpes 2 years after acquisition. Sexually transmitted infections.

Ren, K., Zhang, W., Chen, X., Ma, Y., Dai, Y., Fan, Y., Hou, Y., Tan, R.X., and $\mathrm{Li}$, E. (2016). An Epigenetic Compound Library Screen Identifies BET Inhibitors That Promote HSV-1 and -2 Replication by Bridging P-TEFb to Viral Gene Promoters through BRD4. PLoS pathogens 12, e1005950.

Rivers, T., and Tillett, W.S. (1924). Further observations on th ephenomena encountered in attepting to transmit varecella to rabbits. J Exp Med 39, 777-803.

Roberts, S. (2009). Herpes simplex virus: incidence of neonatal herpes simplex virus, maternal screening, management during pregnancy, and HIV. Curr Opin Obstet Gynecol 21, 124-130.

Rock, D.L., and Fraser, N.W. (1983). Detection of HSV-1 genome in central nervous system of latently infected mice. Nature 302, 523-525.

Roizman, B., Gu, H., and Mandel, G. (2005). The first 30 minutes in the life of a virus: unREST in the nucleus. Cell cycle 4, 1019-1021.

Roizman, B., Knipe, D.M., and Whitley, R.J. (2013). Fields Virology,, Vol 2 ( Lippincott Williams and Wilkins, Philadelphia, PA,).

Roizman, B., and Whitley, R.J. (2013). An Inquiry into the Molecular Basis of HSV Latency and Reactivation. Annual review of microbiology 67, 355-374.

Rosenberg, A.B., Roco, C.M., Muscat, R.A., Kuchina, A., Sample, P., Yao, Z., Graybuck, L.T., Peeler, D.J., Mukherjee, S., Chen, W., et al. (2018). Singlecell profiling of the developing mouse brain and spinal cord with split-pool barcoding. Science 360, 176-182. 
Russell, T.A., and Tscharke, D.C. (2016). Lytic Promoters Express Protein during Herpes Simplex Virus Latency. PLoS pathogens 12, e1005729.

Rziha, H.J., Mettenleiter, T.C., Ohlinger, V., and Wittmann, G. (1986). Herpesvirus (pseudorabies virus) latency in swine: occurrence and physical state of viral DNA in neural tissues. Virology 155, 600-613.

S.E., L., and M.L., H. (1952). A nonhereditary, host-induced variation of bacterial viruses. J Bacteriol 64, 557-569.

Sacks, S.L., Griffiths, P.D., Corey, L., Cohen, C., Cunningham, A., Dusheiko, G.M., Self, S., Spruance, S., Stanberry, L.R., Wald, A., et al. (2004). HSV shedding. Antiviral research 63 Suppl 1, S19-26.

Sadaoka, T., Depledge, D.P., Rajbhandari, L., Venkatesan, A., Breuer, J., and Cohen, J.I. (2016). In vitro system using human neurons demonstrates that varicella-zoster vaccine virus is impaired for reactivation, but not latency. Proceedings of the National Academy of Sciences of the United States of America 113, E2403-2412.

Sadaoka, T., Schwartz, C.L., Rajbhandari, L., Venkatesan, A., and Cohen, J.I. (2018). Human Embryonic Stem Cell-Derived Neurons Are Highly Permissive for Varicella-Zoster Virus Lytic Infection. Journal of virology 92.

Sarno, E., and Robison, A.J. (2018). Emerging role of viral vectors for circuitspecific gene interrogation and manipulation in rodent brain. Pharmacology, biochemistry, and behavior 174, 2-8.

Sawtell, N.M. (1997). Comprehensive quantification of herpes simplex virus latency at the single-cell level. Journal of virology 71, 5423-5431.

Sawtell, N.M. (1998). The probability of in vivo reactivation of herpes simplex virus type 1 increases with the number of latently infected neurons in the ganglia. Journal of virology 72, 6888-6892.

Sawtell, N.M. (2003). Quantitative Analysis of Herpes Simplex Virus Reactivation In Vivo Demonstrates that Reactivation in the Nervous System Is Not Inhibited at Early Times Postinoculation. Journal of virology 77, 4127-4138.

Sawtell, N.M., Bernstein, D.I., and Stanberry, L.R. (1999). A temporal analysis of acyclovir inhibition of induced herpes simplex virus type 1 In vivo 
reactivation in the mouse trigeminal ganglia [In Process Citation]. The Journal of infectious diseases 180, 821-823.

Sawtell, N.M., Poon, D.K., Tansky, C.S., and Thompson, R.L. (1998). The latent herpes simplex virus type 1 genome copy number in individual neurons is virus strain specific and correlates with reactivation. Journal of virology $72,5343-5350$.

Sawtell, N.M., and Thompson, R.L. (1992a). Herpes simplex virus type 1 latency-associated transcription unit promotes anatomical site-dependent establishment and reactivation from latency. Journal of virology 66, 2157-2169.

Sawtell, N.M., and Thompson, R.L. (1992b). Rapid in vivo reactivation of herpes simplex virus in latently infected murine ganglionic neurons after transient hyperthermia. Journal of virology 66, 2150-2156.

Sawtell, N.M., and Thompson, R.L. (2004). Comparison of herpes simplex virus reactivation in ganglia in vivo and in explants demonstrates quantitative and qualitative differences. Journal of virology 78, 7784-7794.

Sawtell, N.M., and Thompson, R.L. (2016). De Novo Herpes Simplex Virus VP16 Expression Gates a Dynamic Programmatic Transition and Sets the Latent/Lytic Balance during Acute Infection in Trigeminal Ganglia. PLoS pathogens 12, e1005877.

Sawtell, N.M., Thompson, R.L., Stanberry, L.R., and Bernstein, D.I. (2001). Early intervention with high-dose acyclovir treatment during primary herpes simplex virus infection reduces latency and subsequent reactivation in the nervous system in vivo. The Journal of infectious diseases 184, 964-971.

Sawtell, N.M., Triezenberg, S.J., and Thompson, R.L. (2011). VP16 serine 375 is a critical determinant of herpes simplex virus exit from latency in vivo. Journal of neurovirology 17, 546-551.

Schiffer, J.T., Abu-Raddad, L., Mark, K.E., Zhu, J., Selke, S., Magaret, A., Wald, A., and Corey, L. (2009). Frequent release of low amounts of herpes simplex virus from neurons: results of a mathematical model. Science translational medicine 1, 7ra16.

Schiffer, J.T., Swan, D.A., Prlic, M., and Lund, J.M. (2018). Herpes simplex virus-2 dynamics as a probe to measure the extremely rapid and spatially 
localized tissue-resident T-cell response. Immunological reviews 285, 113-133.

Schmidt, J.R., and Rasmussen, A.F. (1960). Activation of Latent Herpes Simplex Encephalitis by Chemical Means. The Journal of infectious diseases 106, 154-158.

Scriba, M. (1977). Extraneural localisation of herpes simplex virus in latently infected guinea pigs. Nature 267, 529-531.

Scriba, M. (1981). Persistence of herpes simplex virus (HSV) infection in ganglia and peripheral tissues of guinea pigs. Medical microbiology and immunology 169, 91-96.

Sears, A.E., Hukkanen, V., Labow, M.A., Levine, A.J., and Roizman, B. (1991). Expression of the herpes simplex virus 1 alpha transinducing factor (VP16) does not induce reactivation of latent virus or prevent the establishment of latency in mice. Journal of virology 65, 2929-2935.

Sedarati, F., Izumi, K.M., Wagner, E.K., and Stevens, J.G. (1989). Herpes simplex virus type 1 latency-associated transcription plays no role in establishment or maintenance of a latent infection in murine sensory neurons. Journal of virology 63, 4455-4458.

Sedarati, F., Margolis, T.P., and Stevens, J.G. (1993). Latent infection can be established with drastically restricted transcription and replication of the HSV-1 genome. Virology 192, 687-691.

Sheldrick, P., and Berthelot, N. (1975). Inverted repetitions in the chromosome of herpes simplex virus. Cold Spring Harbor symposia on quantitative biology 39 Pt 2, 667-678.

Shen, W., Sa e Silva, M., Jaber, T., Vitvitskaia, O., Li, S., Henderson, G., and Jones, C. (2009). Two small RNAs encoded within the first 1.5 kilobases of the herpes simplex virus type 1 latency-associated transcript can inhibit productive infection and cooperate to inhibit apoptosis. Journal of virology 83, 9131-9139.

Shimeld, C., Lewkowicz-Moss, S.J., Lipworth, K.M., Hill, T.J., Blyth, W.A., and Easty, D.L. (1986). Antigens of herpes simplex virus in whole corneal epithelial sheets from mice. Archives of ophthalmology 104, 1830-1834. 
Shimeld, C., Tullo, A.B., Easty, D.L., and Thomsitt, J. (1982). Isolation of herpes simplex virus from the cornea in chronic stromal keratitis. The British journal of ophthalmology 66, 643-647.

Simmons, A., Slobedman, B., Speck, P., Arthur, J., and Efstathiou, S. (1992). Two patterns of persistence of herpes simplex virus DNA sequences in the nervous systems of latently infected mice. The Journal of general virology 73, 1287-1291.

Skaper, S.D. (2017). Nerve growth factor: a neuroimmune crosstalk mediator for all seasons. Immunology 151, 1-15.

Smiley, J.R., and Duncan, J. (1997). Truncation of the C-terminal acidic transcriptional activation domain of herpes simplex virus VP16 produces a phenotype similar to that of the in1814 linker insertion mutation. Journal of virology 71, 6191-6193.

Smith, G. (2012). Herpesvirus transport to the nervous system and back again. Annual review of microbiology 66, 153-176.

Southern, E.M. (1975). Detection of specific sequences among DNA fragments separated by gel electrophoresis. J Mol Biol 98, 503-517.

Speck, P.G., and Simmons, A. (1992). Synchronous appearance of antigenpositive and latently infected neurons in spinal ganglia of mice infected with a virulent strain of herpes simplex virus. The Journal of general virology 73 , 1281-1285.

St Leger, A.J., and Hendricks, R.L. (2011). CD8+ T cells patrol HSV-1-infected trigeminal ganglia and prevent viral reactivation. Journal of neurovirology 17 , 528-534.

Stanely, W.M. (1935). Isolation of a crystalline protein possing the properties of tobaccoo -mosaic virus. Science 81, 644-645.

Steiner, I., Spivack, J.G., Deshmane, S.L., Ace, C.I., Preston, C.M., and Fraser, N.W. (1990). A herpes simplex virus type 1 mutant containing a nontransinducing Vmw65 protein establishes latent infection in vivo in the absence of viral replication and reactivates efficiently from explanted trigeminal ganglia. Journal of virology $64,1630-1638$. 
Stern, S., Tanaka, M., and Herr, W. (1989). The Oct-1 homoeodomain directs formation of a multiprotein-DNA complex with the HSV transactivator VP16. Nature 341, 624-630.

Stevens, J.G. (1975a). Herpes simplex viral latency - a review. IARC scientific publications, 67-72.

Stevens, J.G. (1975b). Latent herpes simplex virus and the nervous system. Current topics in microbiology and immunology 70, 31-50.

Stevens, J.G., and Cook, M.L. (1971). Latent herpes simplex virus in spinal ganglia of mice. Science $173,843-845$.

Stevens, J.G., and Cook, M.L. (1973). Latent herpes simplex infection. in: Virus Research ( C F Fox and W S Robinson, eds), Academic Press, New York, 437.

Stevens, J.G., Wagner, E.K., Devi-Rao, G.B., Cook, M.L., and Feldman, L.T. (1987). RNA complementary to a herpesvirus alpha gene mRNA is prominent in latently infected neurons. Science 235, 1056-1059.

Stone, M.J., and Hawkins, C.P. (2007). A medical overview of encephalitis. Neuropsychol Rehabil 17, 429-449.

Straus, S.E., Reinhold, W., Smith, H.A., Ruyechan, W.T., Henderson, D.K., Blaese, R.M., and Hay, J. (1984). Endonuclease analysis of viral DNA from varicella and subsequent zoster infections in the same patient. The New England journal of medicine 311, 1362-1364.

Strelow, L.I., and Leib, D.A. (1995). Role of the virion host shutoff (vhs) of herpes simplex virus type 1 in latency and pathogenesis. Journal of virology 69, 6779-6786.

Sun, Y., Pei, W., Wu, Y., and Yang, Y. (2005). An association of herpes simplex virus type 1 infection with type 2 diabetes. Diabetes Care 28, 435-436.

Tal-Singer, R., Pichyangkura, R., Chung, E., Lasner, T.M., Randazzo, B.P., Trojanowski, J.Q., Fraser, N.W., and Triezenberg, S.J. (1999). The transcriptional activation domain of VP16 is required for efficient infection and establishment of latency by HSV-1 in the murine peripheral and central nervous systems. Virology 259, 20-33. 
Tanemura, S., Yamasaki, T., Katada, K., Hiroshi, and Nishina, H. (2010). Utility and limitations of sp600125 an inhibitor of stress-responsive c-jun n-terminal kinase. Current Enzyme Inhibition 6, 26-33.

Tang, S., Patel, A., and Krause, P.R. (2019). Hidden regulation of herpes simplex virus 1 pre-mRNA splicing and polyadenylation by virally encoded immediate early gene ICP27. PLoS pathogens 15, e1007884.

Tenser, R.B., Dawson, M., Ressel, S.J., and Dunstan, M.E. (1982). Detection of herpes simplex virus mRNA in latently infected trigeminal ganglion neurons by in situ hybridization. Annals of neurology 11, 285-291.

Thellman, N.M., and Triezenberg, S.J. (2017). Herpes Simplex Virus Establishment, Maintenance, and Reactivation: In Vitro Modeling of Latency. Pathogens 6.

Thomas, S.K., Gough, G., Latchman, D.S., and Coffin, R.S. (1999). Herpes simplex virus latency-associated transcript encodes a protein which greatly enhances virus growth, can compensate for deficiencies in immediate-early gene expression, and is likely to function during reactivation from virus latency. Journal of virology 73, 6618-6625.

Thomas, S.K., Lilley, C.E., Latchman, D.S., and Coffin, R.S. (2002). A protein encoded by the herpes simplex virus (HSV) type 1 2-kilobase latencyassociated transcript is phosphorylated, localized to the nucleus, and overcomes the repression of expression from exogenous promoters when inserted into the quiescent HSV genome. Journal of virology 76, 4056-4067.

Thompson, R.L., Preston, C.M., and Sawtell, N.M. (2009). De novo synthesis of VP16 coordinates the exit from HSV latency in vivo. PLoS pathogens 5, e1000352.

Thompson, R.L., and Sawtell, N.M. (1997). The herpes simplex virus type 1 latency-associated transcript gene regulates the establishment of latency. Journal of virology $71,5432-5440$.

Thompson, R.L., and Sawtell, N.M. (2000). Replication of herpes simplex virus type 1 within trigeminal ganglia is required for high frequency but not high viral genome copy number latency. Journal of virology 74, 965-974. 
Thompson, R.L., and Sawtell, N.M. (2001). Herpes simplex virus type 1 latency-associated transcript gene promotes neuronal survival. Journal of virology $75,6660-6675$.

Thompson, R.L., and Sawtell, N.M. (2006). Evidence that the herpes simplex virus type 1 ICP0 protein does not initiate reactivation from latency in vivo. Journal of virology $80,10919-10930$.

Thompson, R.L., and Sawtell, N.M. (2011). The herpes simplex virus type 1 latency associated transcript locus is required for the maintenance of reactivation competent latent infections. Journal of neurovirology 17 , 552-558.

Thompson, R.L., and Sawtell, N.M. (2019). Targeted Promoter Replacement Reveals That Herpes Simplex Virus Type-1 and 2 Specific VP16 Promoters Direct Distinct Rates of Entry Into the Lytic Program in Sensory Neurons in vivo. Frontiers in microbiology 10.

Toma, H.S., Murina, A.T., Areaux, R.G., Jr., Neumann, D.M., Bhattacharjee, P.S., Foster, T.P., Kaufman, H.E., and Hill, J.M. (2008). Ocular HSV-1 latency, reactivation and recurrent disease. Seminars in ophthalmology 23, 249-273.

Traina-Dorge, V., Palmer, B.E., Coleman, C., Hunter, M., Frieman, A., Gilmore, A., Altrock, K., Doyle-Meyers, L., Nagel, M.A., and Mahalingam, R. (2019). Reactivation of Simian Varicella Virus in Rhesus Macaques after CD4 T Cell Depletion. Journal of virology 93.

Treat, B.R., Bidula, S.M., Ramachandran, S., St Leger, A.J., Hendricks, R.L., and Kinchington, P.R. (2017). Influence of an immunodominant herpes simplex virus type $1 \mathrm{CD} 8+\mathrm{T}$ cell epitope on the target hierarchy and function of subdominant CD8+ T cells. PLoS pathogens 13, e1006732.

Tullo, A.B., Easty, D.L., Shimeld, C., Stirling, P.E., and Darville, J.M. (1985). Isolation of herpes simplex virus from corneal discs of patients with chronic stromal keratitis. Transactions of the ophthalmological societies of the United Kingdom 104 ( Pt 2), 159-165.

Uitdehaag, J.C., Verkaar, F., Alwan, H., de Man, J., Buijsman, R.C., and Zaman, G.J. (2012). A guide to picking the most selective kinase inhibitor tool compounds for pharmacological validation of drug targets. British journal of pharmacology 166, 858-876. 
Underwood, G.E., and Weed, S.D. (1974). Recurrent cutaneous herpes simplex in hairless mice. Infect Immun 10, 471-474.

Vidal, E. (1873). Inoculabilite des pustules d'ecthyma. Ann Derm Syphiligr 4, 350-358.

Visser, M.R., and Vercellotti, G.M. (1993). Herpes simplex virus and atherosclerosis. Eur Heart J 14 Suppl K, 39-42.

Von Barensprung, F.G.F. (1863). Beitrage zur Kenntnis des Zoster. Annalen Charite-Krunkenhauses zu Berlin 11, 96-104.

von Bokay, J. (1909). Uber den a"tiologischen Zusammenhang der Varizellen mit gewissen Fa"llen von Herpes Zoster. Wien Klin Wochenschr 22, 1323-1326.

Wang, F., Tang, W., McGraw, H.M., Bennett, J., Enquist, L.W., and Friedman, H.M. (2005a). Herpes simplex virus type 1 glycoprotein $e$ is required for axonal localization of capsid, tegument, and membrane glycoproteins. Journal of virology $79,13362-13372$.

Wang, F., Zumbrun, E.E., Huang, J., Si, H., Makaroun, L., and Friedman, H.M. (2010). Herpes simplex virus type 2 glycoprotein $E$ is required for efficient virus spread from epithelial cells to neurons and for targeting viral proteins from the neuron cell body into axons. Virology 405, 269-279.

Wang, K., Lau, T.Y., Morales, M., Mont, E.K., and Straus, S.E. (2005b). Lasercapture microdissection: refining estimates of the quantity and distribution of latent herpes simplex virus 1 and varicella-zoster virus DNA in human trigeminal Ganglia at the single-cell level. Journal of virology 79 , 14079-14087.

Wang, X., Helfer, C.M., Pancholi, N., Bradner, J.E., and You, J. (2013). Recruitment of Brd4 to the human papillomavirus type 16 DNA replication complex is essential for replication of viral DNA. Journal of virology 87 , 3871-3884.

Washington, S.D., Edenfield, S.I., Lieux, C., Watson, Z.L., Taasan, S.M., Dhummakupt, A., Bloom, D.C., and Neumann, D.M. (2018a). Depletion of the Insulator Protein CTCF Results in Herpes Simplex Virus 1 Reactivation In Vivo. Journal of virology 92. 
Washington, S.D., Edenfield, S.I., Lieux, C., Watson, Z.L., Taasan, S.M., Dhummakupt, A., Bloom, D.C., and Neumann, D.M. (2018b). Depletion of the insulator protein CTCF results in HSV-1 reactivation in vivo. Journal of virology.

Washington, S.D., Singh, P., Johns, R.N., Edwards, T.G., Mariani, M., Frietze, S., Bloom, D.C., and Neumann, D.M. (2019). The CCCTC Binding Factor, CTRL2, Modulates Heterochromatin Deposition and the Establishment of Herpes Simplex Virus 1 Latency In Vivo. Journal of virology 93.

Watson, J.D., and Crick, F.H. (1953). The structure of DNA. Cold Spring Harbor symposia on quantitative biology 18, 123-131.

Watson, K., Stevens, J.G., Cook, M.L., and Subak-Sharpe, J.H. (1980). Latency competence of thirteen HSV-1 temperature-sensitive mutants. The Journal of general virology 49, 149-159.

Watson, Z.L., Washington, S.D., Phelan, D.M., Lewin, A.S., Tuli, S.S., Schultz, G.S., Neumann, D.M., and Bloom, D.C. (2018). In Vivo Knockdown of the Herpes Simplex Virus 1 Latency-Associated Transcript Reduces Reactivation from Latency. Journal of virology 92, e00812-00818.

Webre, J.M., Hill, J.M., Nolan, N.M., Clement, C., McFerrin, H.E., Bhattacharjee, P.S., Hsia, V., Neumann, D.M., Foster, T.P., Lukiw, W.J., et al. (2012). Rabbit and mouse models of HSV-1 latency, reactivation, and recurrent eye diseases. Journal of biomedicine and biotechnology 2012, 612316.

Wechsler, S.L., Nesburn, A.B., Watson, R., Slanina, S.M., and Ghiasi, H. (1988). Fine mapping of the latency-related gene of herpes simplex virus type 1: alternative splicing produces distinct latency-related RNAs containing open reading frames. Journal of virology 62, 4051-4058.

Whitlow, Z., and Kristie, T.M. (2009). Recruitment of the transcriptional coactivator HCF-1 to viral immediate-early promoters during initiation of reactivation from latency of herpes simplex virus type 1 . Journal of virology 83, 9591-9595.

Wilcox, C.L., Crnic, L.S., and Pizer, L.I. (1992). Replication, latent infection, and reactivation in neuronal culture with a herpes simplex virus thymidine kinase-negative mutant. Virology 187, 348-352. 
Wilcox, C.L., and Johnson, E.M., Jr. (1987). Nerve growth factor deprivation results in the reactivation of latent herpes simplex virus in vitro. Journal of virology 61, 2311-2315.

Wilcox, C.L., and Johnson, E.M., Jr. (1988). Characterization of nerve growth factor-dependent herpes simplex virus latency in neurons in vitro. Journal of virology 62, 393-399.

Wilcox, C.L., Smith, R.L., Freed, C.R., and Johnson, E.M., Jr. (1990). Nerve growth factor-dependence of herpes simplex virus latency in peripheral sympathetic and sensory neurons in vitro. The Journal of neuroscience : the official journal of the Society for Neuroscience 10, 1268-1275.

Wildy, P. (1973). Herpes: history and classification. In: Kaplan, AS ed, The Herpesviruses, Academic Press NY, NY.

Wysocka, J., and Herr, W. (2003). The herpes simplex virus VP16-induced complex: the makings of a regulatory switch. Trends in biochemical sciences 28, 294-304.

Yanez, A.A., Harrell, T., Sriranganathan, H.J., Ives, A.M., and Bertke, A.S. (2017). Neurotrophic Factors NGF, GDNF and NTN Selectively Modulate HSV1 and HSV2 Lytic Infection and Reactivation in Primary Adult Sensory and Autonomic Neurons. Pathogens 6.

Yang, L., Voytek, C.C., and Margolis, T.P. (2000). Immunohistochemical analysis of primary sensory neurons latently infected with herpes simplex virus type 1. Journal of virology 74, 209-217.

Yu, X., and He, S. (2016). The interplay between human herpes simplex virus infection and the apoptosis and necroptosis cell death pathways. Virology journal 13,77 .

Zargar, Z., and Tyagi, S. (2012). Role of host cell factor-1 in cell cycle regulation. Transcription 3, 187-192.

Zerboni, L., and Arvin, A. (2015). Neuronal Subtype and Satellite Cell Tropism Are Determinants of Varicella-Zoster Virus Virulence in Human Dorsal Root Ganglia Xenografts In Vivo. PLoS pathogens 11, e1004989.

Zerboni, L., Sen, N., Oliver, S.L., and Arvin, A.M. (2014). Molecular mechanisms of varicella zoster virus pathogenesis. Nature reviews Microbiology 12, 197-210. 
Zheng, Y., Liu, L., and Shukla, G.C. (2017). A comprehensive review of webbased non-coding RNA resources for cancer research. Cancer letters 407, $1-8$. 
